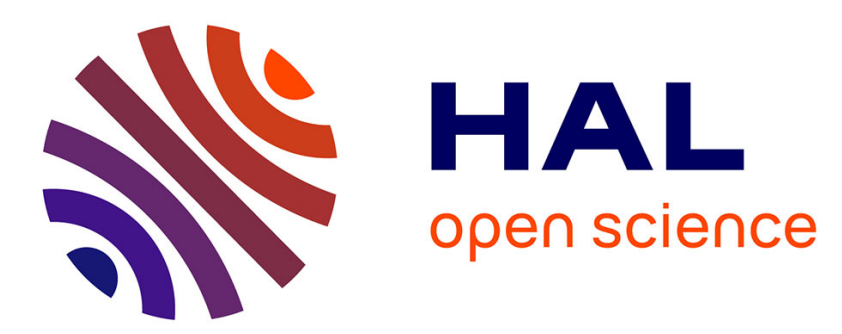

\title{
A Review on Graphical Methods for Modeling a Proton Exchange Membrane (PEM) Fuel Cell
}

Mathieu Bressel, Belkacem Bouamama, Daniel Hissel, Mickaël Hilairet

\section{To cite this version:}

Mathieu Bressel, Belkacem Bouamama, Daniel Hissel, Mickaël Hilairet. A Review on Graphical Methods for Modeling a Proton Exchange Membrane (PEM) Fuel Cell. Journal of Fuel Cell Science and Technology, 2015, 12 (6), pp.FC-14-1108 (19). 10.1115/1.4032336 . hal-02380399

\section{HAL Id: hal-02380399 \\ https://hal.science/hal-02380399}

Submitted on 26 Nov 2019

HAL is a multi-disciplinary open access archive for the deposit and dissemination of scientific research documents, whether they are published or not. The documents may come from teaching and research institutions in France or abroad, or from public or private research centers.
L'archive ouverte pluridisciplinaire HAL, est destinée au dépôt et à la diffusion de documents scientifiques de niveau recherche, publiés ou non, émanant des établissements d'enseignement et de recherche français ou étrangers, des laboratoires publics ou privés. 


\title{
A Review on Graphical Methods for Modeling a PEM Fuel Cell
}

\author{
Mathieu Bressel \\ FCLAB, FR CNRS 3539, \\ CRIStAL, UMR CNRS 9189, \\ Avenue Paul Langevin, \\ 59655 Villeneuve d' Ascq, France \\ Email: Mathieu.Bressel@polytech-lille.fr \\ Belkacem Ould Bouamama \\ CRIStAL, UMR CNRS 9189, \\ Avenue Paul Langevin, \\ 59655 Villeneuve d' Ascq, France \\ Email: Belkacem.Ouldbouamama@polytech-lille.fr \\ Daniel Hissel \\ FEMTO-ST, UMR CNRS 6174, \\ FCLAB, FR CNRS 3539, \\ Rue Thierry Mieg, \\ 90000 Belfort, France \\ Email: Daniel.Hissel@univ-fcomte.fr \\ Mickael Hilairet \\ FEMTO-ST, UMR CNRS 6174, \\ FCLAB, FR CNRS 3539, \\ Rue Thierry Mieg, \\ 90000 Belfort, France \\ Email: Mickael.Hilairet@univ-fcomte.fr
}

\begin{abstract}
Fuel cell systems represent a promising alternative energy converter. For the last years, researches have been conducted for their modeling, control and diagnosis. That model should accurately reproduce the behavior without being too complex. Due to the highly multi-physical interactions and coupling within the fuel cell, using a graphical representation for developing this model seems well suited. This paper presents a review of recent literature on graphical representation of proton exchange membrane fuel cell (PEMFC). Three main graphical representations are discussed: Bond Graph, Energetic Macroscopic Representation and Equivalent Electrical Circuit. Their fields of application will be shown as well.
\end{abstract}

\section{Introduction}

Energy consumption is steadily growing while global fossil resources are diminishing. Moreover, air pollution is one of the major challenges of the coming decades [1]. An energetic transition has to begin. The fuel cell and especially the proton exchange membrane fuel cell (PEMFC) appears as an opportunity to face those challenges. However, many issues have to be tackled to make this new generation of electric power converter competitive. In fact, the overall efficiency of a fuel cell system is still quite low, and it's not sufficiently reliable for mass industrialization [2]. Various progresses still have to be made for developing this emerging technology, including optimization of overall efficiency and lifespan. These two areas 
require a better understanding of the multiple interactions and coupling within a fuel cell stack. In the past years, numerous publications have presented analytic fuel cell models. Most papers focus on designing an efficient fuel cell stack and are based on mechanistic models as summarized by Biyikoglu et al. [3]. The system is usually described by partial differential and algebraic equations. Mechanistic models allow for instance understanding the hydration process in the membrane, the mass and charging transfer as well as the diffusion of gases. They are used for a quantitative analysis and a monitoring purpose. They offer a very good description of the internal physical phenomenon. Springer et al. [4], Amphlett et al. [5] and Costamagna et al. [6] present PEMFC models taking care of the mass and energy conservation laws and provide some transient responses. The latest, as well as Lee et al. [7], use finite difference method to model the fuel cell behavior in a multidimensional framework. Hontanon et al. [8] show how to enhance the performances of a fuel cell stack by simulating the gas flow distribution within the device.

In general, PEMFC analytic models suffer from several issues. Firstly, the PEMFC system is complex and involves the coupling of many subsystems from different energy domains (electrical, mechanical, electro-chemical, thermo-fluidic). The behavior is typically defined by high-order non-linear differential equations that are hard to define and hard to analyze using analytical or numerical schemes. Secondly, even if the model structure can be derived accurately, numerical values of the system parameters are difficult to obtain, affecting the overall quantitative model accuracy. As part of the qualitative modeling methods, a graphical model is a structural representation of the system topology (showing the existence of the links between variables) and is adapted for complex multi-physical systems. Links in the graph connect variable nodes and equation nodes. The graph structures are independent from the numerical values of the system parameters, so graphical methods are well suited for qualitative diagnosis or control analysis [9] [10]. Furthermore, the graphical model structure is general, and accommodates relations that are linear, nonlinear, or even expressed in table format. The purpose of graphical modeling is to present structurally and / or functionally the system with only one formalism for any physical domain. It allows a macroscopic analysis and an easier interpretation of the exchange of power (when an energetic representation is use) which is important when designing an energy management strategy. This is the reason why this kind of model is well suited for PEMFC [11].

The originality and objective of this paper is to describe and compare several graphical representations in the modeling methodology, energy domain, tools, and application. It also presents a review of their applications to a PEMFC and proposes a comparison based on the modeling boundaries, purpose of the model and on the modeled phenomena. The first section recalls the graphical representations available in the literature and their interests. In the second section, a survey on PEMFC's graphical representation is detailed. A classification and synthesis of those representations is detailed in the third section. A conclusion is given in the last section.

\section{Graphical representation of systems}

The common idea for graphical representation is to unify the different physical laws within a unique formalism. Graphical models $G(S, A)$ capture system structure by representing the set of system variables and system behavior equations $\{S\}$ as nodes [12]. The mutual influences between variables and equations are represented by a set of edges $\{A\}$. The main graphical representations that are often encountered for modeling are:

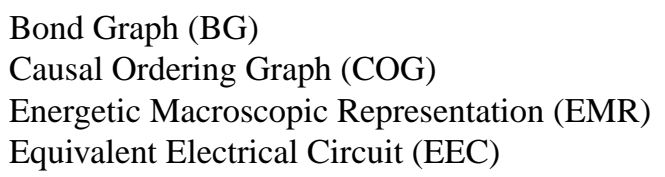

Among others qualitative graph based methods, one can cite also Directed Graph (where $S$ is a set of inputs, linear state variables and output variables) [12], Causal Graph (where $S$ is a set of relations and measured variables), Temporal Causal Graphs (TCGs) and Signed Directed Graphs (SDG) [13]. TCGs formally capture causal and temporal relations among system variables in a common framework. Temporal evolution of the variables is represented qualitatively on causal edges as integrals or delays between pairs of variables [14]. One can cite also Power Flow Diagram (PFD) [15]. This formalism is derived from the Bond Graph and so can use the analysis tools already developed. All those representations were not use for PEMFC modeling and are out of the scope of this paper.

\subsection{Bond Graph (BG)}

A bond graph is a unified graphical language used to model multi-physical systems based on power exchange. BG is a graph $G(S, A)$, where $\mathrm{S}$ represents physical components, subsystems, and other basic elements called junctions, while the edges $A$, called power bonds represent the power exchanged between nodes. This power is labelled by two conjugated power variables, named effort $(e)$, and flow $(f)$. The key to bond graph modeling is the representation (by a bond) of exchanged power as the product of efforts and flows $P=e f$, with elements acting between these variables and junction structures to put the subsystems together. As shown in Fig. 1 (a), the power exchanged between two systems A and B indicated by a bond is 
the product of two variables: a potential variable (e.g. pressure, electrical potential, temperature, chemical potential, force, etc.) called effort (e) and a derivative of extensive variable called flow (f) (e.g. volume flow, current, entropy flow, velocity, molar flow, etc.).

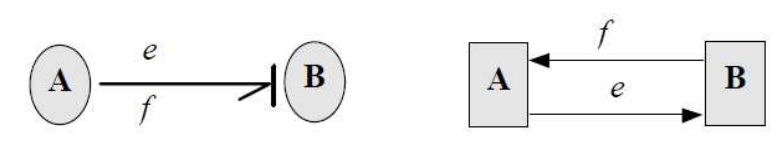

Fig. 1. Bond Graph representation (a) and causality (b)

One important structural property of the bond graph is its causality concept. Indeed, the determination of causes and effects in the system is directly deduced from the graphical representation. In the bond graph, it is denoted by the cross-stroke on the right indicating that the effort acts to the right. The side of the cross-stroke for the flow is in the reverse direction. As example in Fig. 1 (a), assigned causality means that system A imposes efforts on B. In the corresponding block diagram given by the Fig. 1(b), the direction of action is indicated by an arrow on each connection as illustrated. Independently of the causality, the direction of the positive power is indicated by the half-arrow on the bond. The bond graph uses the notion of integral causality but, do not consider it mandatory. If the model does not allow the interconnection of two elements with respect to the integral causality, the BG formalism offers the possibility to use derived causality and so remain close to the structural representation of the system. The derivative causality is specially used for Analytical redundancy Relations Generation (ARR) for diagnosis purpose while the initial conditions in the real process are not known [16].

In BG, there is a limited set of possible elements to represent the behavior of a physical system $S=\{R \cup C \cup I \cup T F \cup$ $G Y \cup S e \cup S f \cup D e \cup D f \cup J\}$. Where, the R-element represents a passive energy dissipation element, while C, and I model the passive energy storage elements. (Se), and (Sf) are the sources of effort and flow, respectively. Sensors are represented by flow (Df), and effort (De) detectors. Finally, J (which can be a zero or a one junction), is used to connect the elements having the same effort ( 0 -junction), or flow ( 1 -junction). The conservative energy laws are obtained from the latter. The TF element stands for a transformer and is defined by the relations: $\left\{e_{1}=m e_{2} ; f_{2}=m f_{1}\right\}$, the gyrator GY is defined by $\left\{e_{1}=r f_{2}\right.$; $\left.e_{2}=r f_{1}\right\}$. The passive elements are described by generic constitutive equations. R-elements (electrical resistor, mechanical damper, etc.) are dissipative and they are modeled by algebraic equations that link the effort and the flow. Potential storage energy, C-elements (electrical capacitor, spring stiffness, reservoir, etc.) are quantified by the equation relating the effort with the integral of the flow (called displacement). Also kinetic storage energy, I-elements (mechanical inertia, electrical inductance, etc.) are described by a dual equation linking the flow with the integral of the effort (called momentum). All those elements are summarized and represented in Appendix A. True bond graphs in thermal and chemical engineering introduce complex variables like entropy and chemical potential, which do not obey simple conservation laws. Thus, such processes are represented usefully by pseudo bond graphs, where the product of effort and flow variable is not a power. In the chemical systems the power variables, modeling the chemical transformation of the reaction, and those modeling the kinetic phenomena of the reaction can be distinguished. Regarding transformation phenomenon of the reaction, is used the pair $(\mu, \dot{n})$ (the effort is the chemical potential $\mu\left(\mathrm{J} \mathrm{mol}^{-1}\right)$ and the flow is the molar flow $\dot{n}\left(\mathrm{~mol} \mathrm{~s}^{-1}\right)$. In the convection thermal energy domain (Lagrangian point of view), is used as power variables the pair temperature-enthalpy flow $(T, \dot{H})$ or the pair specific enthalpy $h\left(J \mathrm{~kg}^{-1}\right)$-enthalpy flow $\dot{H}$. In case of thermal conduction (Eulerian point of view), the pair temperature-thermal flow $(T, \dot{Q})$ is used. In Tab. 1 is given effort and flow variables used in process engineering.

The power of the bond graph formalism lies in the multiple tools developed: observability, controllability, diagnostic and dedicated software [17] [18] [16]. Therefore, it makes the BG an interesting tool for modeling and then studying the behavior of a PEMFC. Because of its graphical and structural aspect, a novel formalism named Signed Bond Graph (SBG) has been presented for transportation [19], PEMFC modeling and diagnosis application [20]. This formalism exploits its qualitative and quantitative structural properties enabling the generation of multiple behavior predictions.

\subsection{Causal Ordering Graph (COG)}

The Causal Ordering Graph $G(S, A)$ is a graphical representation created to model a system in full respect to the integral causality. $S$ represents the set of constitutive elements of this graphical language, while $A$ stands for the effort or flow. But unlike the BG, the Causal Ordering Graph does not use an energetic approach and not necessary the generalized variables from Table. 1. The COG formalism admits a set of three elements called processors $S=\{$ source $\cup$ rigid $\cup$ causal $\}$. The source processor imposes an effort or a flow without being influenced by the input, so its causality is implicit. The rigid processor represents the acausal and atemporal relationship (represented by a double arrow within an ellipse). The double arrow specifies the reversibility of the relationship. The causality depends on other processors connected to it. The causal processor is represented by a single arrow within an ellipse. For this latest, the relationship depends on the time and the causality is intrinsic to the object. The single arrow reflects the non-reversible nature of the relationship in a causal way [21]. 


\begin{tabular}{|c|c|c|}
\hline Domain & Effort & Flow \\
\hline Electrical & Voltage $u(\mathrm{~V})$ & Current $i$ (A) \\
\hline Mechanical (translation) & Force $F(\mathrm{~N})$ & Velocity $v\left(\mathrm{~m} \mathrm{~s}^{-1}\right)$ \\
\hline Mechanical (rotation) & Torque $\Gamma(\mathrm{N} \mathrm{m})$ & Angular velocity $\omega\left(\operatorname{rad~s}^{-1}\right)$ \\
\hline Hydraulic & Pressure $P(\mathrm{~Pa})$ & Volume flow $\frac{d V}{d t}\left(\mathrm{~m}^{3} \mathrm{~s}^{-1}\right)$ \\
\hline \multirow[t]{3}{*}{ Thermal } & Temperature $T(\mathrm{~K})$ & Enthalpy flow $\frac{d H}{d t}\left(\mathrm{~J} \mathrm{~s}^{-1}\right)$ \\
\hline & Temperature $T(\mathrm{~K})$ & Entropy flow $\frac{d S}{d t}\left(\mathrm{~J}(\mathrm{~K} \mathrm{~s})^{-1}\right)$ \\
\hline & Temperature $T(\mathrm{~K})$ & Heat flow $\frac{d Q}{d t}\left(\mathrm{~J} \mathrm{~s}^{-1}\right)$ \\
\hline Chemical (transformation) & Chemical potential $\mu\left(\mathrm{J} \mathrm{mol}^{-1}\right)$ & Molar flow $\frac{d n}{d t}\left(\mathrm{~mol} \mathrm{~s}^{-1}\right)$ \\
\hline Chemical (kinetic) & Chemical affinity $A\left(\mathrm{~J} \mathrm{~mol}^{-1}\right)$ & Speed of reaction $\frac{d n}{d t}\left(\mathrm{~mol} \mathrm{~s}^{-1}\right)$ \\
\hline
\end{tabular}

Table 1. Generalized power variables [17]

The coupling between variables can be expressed with an arrow connected to two rigid processors. It ensures the conservation of the instantaneous power. Two couplings can be distinguished: the modulator (similar to transformer) when the energetic nature is conserved and the gyrator when the energetic nature is different on each side of the processor. The rigid relations are weighted by a coefficient called respectively modulation factor or gyration factor. The clear view of the causality allows identifying easily the state variables, which is the main concern for designing a control architecture. By applying inverting rules, the control scheme can be established [22]. The Fig. 2. shows the rigid and causal processors and its associated control. The major drawback of such approach is the loss of legibility in a complex model [23].
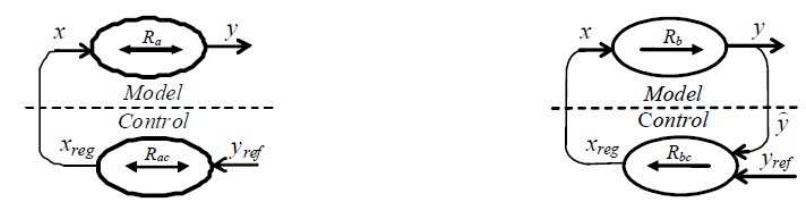

Fig. 2. Static and dynamic processors and their associated control [23]

\subsection{Energetic Macroscopic Representation (EMR)}

The Energetic Macroscopic Representation $G(S, A)$ is an extension of the COG to more complex physical processes. This graphical representation was initially created to model electromechanical systems and then was extended to other field of physics. S represents the set of constitutive elements of this graphical language, while A stands for the exchange of power between those elements. The transfer of energy between two subsystems is represented by two arrows; one carries the effort -potential variable- (e) while the other stands for the flow -kinetic variable- (f). The result of the product of those two conjugated variables is the power flow $P=e f$. The EMR formalism lies on the principle of action-reaction: for any action of an environment on a system, the system induces a reaction on this environment. Moreover, when the action is from a potential nature, it induces a kinetic reaction and inversely. Fig. 3 shows the EMR of a battery (source of effort) which impose a voltage (action) depending on the load connected to it (reaction). The Energetic Macroscopic Representation also uses the generalized power variables (refer to Table. 1). One major difference with the bond graph concerns the causality. The EMR formalism always respects the integral causality which is shown by the sense of the arrows.

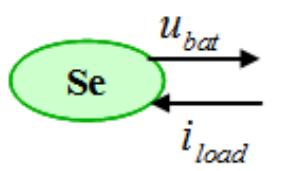

Fig. 3. A source of effort (battery) in EMR 
The EMR admits a set of four elements $S=\{$ sources $\cup$ energystorage $\cup$ energy conversion $\cup$ energydistribution $\}$. Sources (represented by a green oval), can deliver or receive an effort or a flow and can be perturbed by the conjugated input variable. It is used to represent a natural source (e.g. battery) or a fictive equivalent source (e.g. fuel cell). Energy storage elements (represented by a rectangle with its diagonal orange) stands for the accumulation of energy with or without losses (e.g. reservoir, mechanical inertia, electrical capacitor). It should be noted that the EMR formalism does not distinguish the accumulation of potential energy and kinetic energy. This element imposes the causality to the others and so, several energy storage elements cannot be directly connected unless there is no conflict of causality. The formalism admits rules to avoid this conflict of causality [24]. The energy conversion element (represented by an orange square for monophysical conversion and an orange circle for multiphysical conversion) ensures the transfer of power without loss or accumulation (equivalent to the transformer and gyrator from the bond graph formalism). This element can have a tuning vector (e.g. duty cycle for a DC chopper). The energy distribution element (several squares for monophysical or circles for multiphysical which intersect) can be considered as a plurality of conversion elements that share a common physical resource. One gathers energy from several upstream channels to a common downstream channel (e.g. a field winding DC machine). The dual element distributes the energy from an upstream channel to several downstream channels (e.g. a mechanical differential). Those elements are presented in appendix B.

The strength of the EMR lies in an extension called Maximum Control Structure(MCS) [25] [26]. It allows designing architecture of control based on model inversions. The integral causality does not allow the direct inversion of accumulative elements. Therefore, this problem is solved by using correctors or observers. To remove the unrealistic measurements and to take into account the limitation of the model (validation range), one can use the Practical Command Structure (PCS) [26]. The resulting control structure is implementable on real time and shows the necessary sensors. This is one of the reasons why this formalism is used for PEMFC modeling.

\subsection{Equivalent Electrical Circuit (EEC)}

The Equivalent Electrical Circuit represents a system by electrical formalism based on the Kirchoff's laws; energy, charge, and matter are always conserved. Those fundamental principles can be extrapolated to other physical domain such as hydraulic or pneumatic [27]. Every elements of a system is represented by an equivalent electrical circuit (e.g. electrical current and fluid flow is expressed by a similar mathematical formula). The integral causality is respected. This representation is well suited for a system approach, especially when it includes electrical equipment [28]. This formalism is mastered by many, contributing to its deployment in the fuel cell community. Small signal models only show the dynamical behavior for a specific operational point and are out of the scope of this paper. Only large signal models of PEMFC will be discussed.

\section{Literature survey of graphical representation of PEMFC}

For many years, the modeling of PEMFC attracts experts in various fields. The objective of this modeling can be multiple. The modeling can be performed for the simulation of the system, for the design, for the control or the diagnostic as well. It follows that the granularity of the proposed model is correlated to the purpose. A simulation model must take into account all the phenomena involved in the PEMFC, while a control-oriented model should be simple enough in order to reduce the computational complexity and enable on-line implementation. This section presents a literature survey on graphical representations for PEMFC stacks and systems.

\subsection{Description of a PEMFC}

A PEMFC (Fig. 4) is an electrochemical converter which converts the chemical energy of hydrogen and oxygen into DC electricity flowing in an external electrical load. It is based on the reverse principle of electrolysis. At the anode, the hydrogen provided through the channels of the bipolar plates is diffused through the Gas Diffusion Layer (GDL) to the electrolyte, where the reaction

$$
H_{2} \rightarrow 2 H^{+}+2 e^{-}
$$

occurs. The proton exchange membrane is designed for transporting the $\mathrm{H}^{+}$ion to the cathode while the transfer of the other species is limited.The cathode compartment brings through the GDL to the reaction interface the oxygen necessary for the following exothermic reaction:

$$
2 \mathrm{H}^{+}+\frac{1}{2} \mathrm{O}_{2}+2 e^{-} \Rightarrow \mathrm{H}_{2} \mathrm{O}+\text { heat }
$$

Both reactions create a potential difference between the two electrodes. This thermodynamic potential results from the Gibbs free energy G, and is calculated based on the chemical affinity of the species: $E 0=\frac{-\Delta G}{n F}$ where $\mathrm{F}$ is the Faraday number 
and $\mathrm{n}$ is the number of moles of electron exchanged. This potential is corrected in temperature and pressure by the Nernst equation:

$$
E=E 0+\frac{R T}{2 F}\left(\frac{P_{\mathrm{H}_{2}} P_{\mathrm{O}_{2}}^{0.5}}{P_{\mathrm{H}_{2} \mathrm{O}}}\right)
$$

This is the maximum theoretical potential that a PEMFC can reach. However, the kinetics of reaction cause losses named activation losses and generate an over-voltage which is subtracted from the theoretical potential (calculated above). Furthermore, the resistivity of the membrane electrode assembly (MEA) decreases the operational potential by ohmic effect. The resistance value depends on the degree of humidification of the membrane and on the temperature. Finally, species are consumed and implies a loss of partial pressure on the reaction surfaces and therefore significantly reduces the Nernst potential, especially at high currents. This phenomenon is called diffusion / concentration losses.

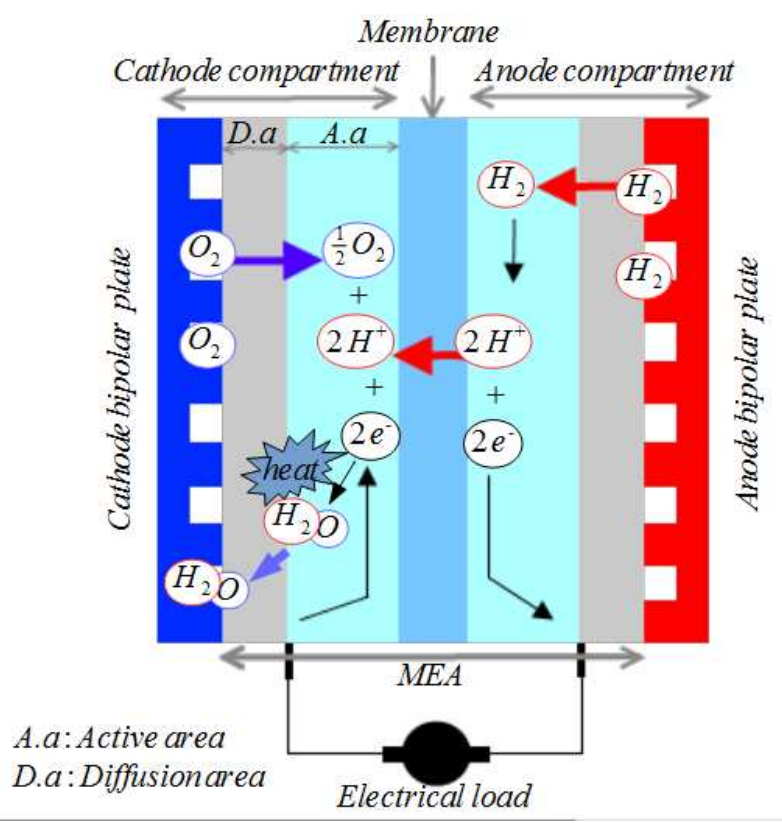

Fig. 4. Principle of operation of a PEM

These losses and the chemical reactions generate heat that must be evacuated by means of a cooling system. Moreover, during transients, one can observe an electron accumulation along the membrane electrode interface. It is the double layer capacitance effect [29]. It is important to note that most of the phenomenon described above depends on one another (e.g. the over-potentials depend on the temperature, and the temperature depends on the heat created by the losses and also on the behavior of the cooling circuit). Because of these couplings, it is interesting to decompose functionally the PEMFC model [30].

\subsection{Bond Graph (BG) model of a Fuel Cell}

Peraza et al. [31] present a static model (potential storage phenomena, represented by C BG element and inertia phenomena given by I elements are not considered) of a PEMFC stack. This representation (Fig. 5) shows the activation losses $V_{a c t}$ in both anode and cathode (using the Tafel's equation), the diffusion loss $V_{\text {diff }}$ at the cathode (Butler-Volmer's law) by modulated sources of effort Mse and the ohmic losses by a resistive element R.

$$
\begin{gathered}
V_{a c t}=A \ln \left(\frac{i}{i_{0}}\right) \\
V_{d i f f}=B \operatorname{asinh}\left(\frac{i}{2 i_{0}\left(1-\frac{i}{i_{L}}\right)}\right)
\end{gathered}
$$


with $A$ and $B$, the Tafel constants, $i_{0}$ the exchange current density, $i_{L}$ the limit current density and $i$ the load current. The paper considers no pressure losses, a constant temperature and a well-maintained humidification of the membrane. The model is validated using the dedicated BG software 20-Sim and an experimental polarization curve of a commercial fuel cell is provided. This model is simple but represents well the physical structure of the fuel cell. It predicts the static behavior with an average error of $1,18 \%$.

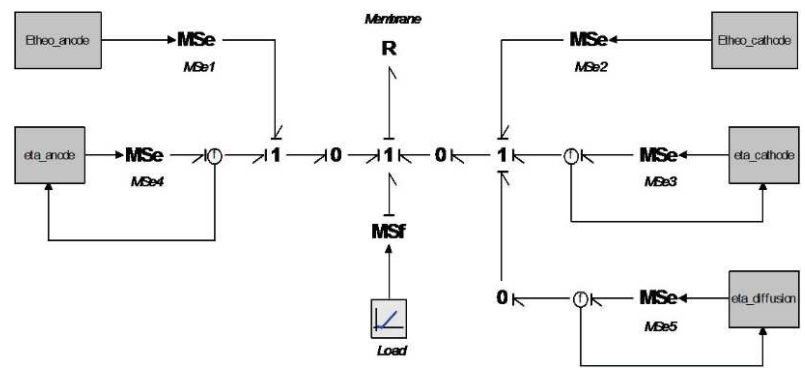

Fig. 5. Bond graph of a PEMFC stack [31]

Rabih et al. [32], describe thanks to BG the hydraulic part of a fuel cell. The channels that bring the gases and water can be modeled by dissipative and capacitive elements. Because of the viscosity, the flow of fluids creates friction and follow this law: $\Delta P=R_{\text {hydra }} \dot{V}$ where $\Delta P$ is the pressure loss, $R_{\text {hydra }}$ is the hydraulic resistance (it depends on the geometrical parameters of the channels and the viscosity of the gas). The capacitive element $\mathrm{C}$ represents the storage of gases under pressure. The tank and pipes feeding the fuel cell with gases are also represented by an hydraulic losses (R element) and mass storage (C element). This model (Fig. 6) was included in a global model to study the influence of the current and temperature on the pressure losses. Finally the paper shows the influence of channel dimensions on the pressure losses, and uses the model for designing the channel diameter.

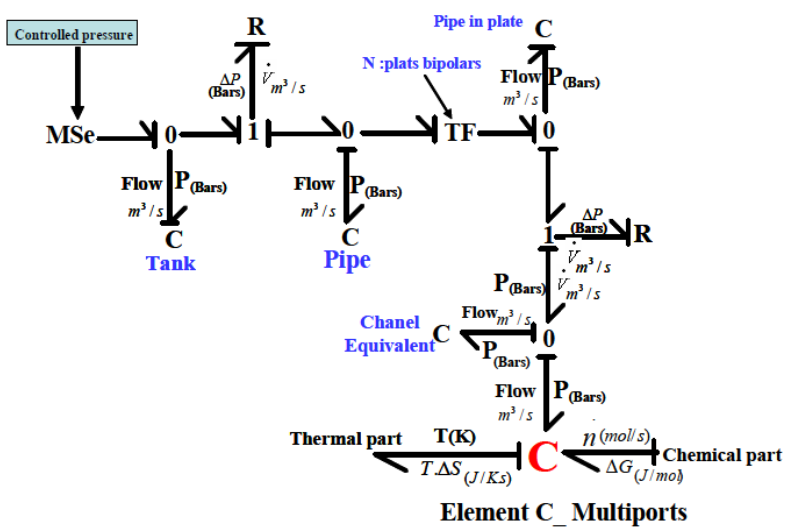

Fig. 6. Bond graph of the hydraulic part of a PEMFC [32]

Saisset et al. [33] describe a separated electrodes bond graph model of a PEMFC stack (refer to Fig. 7). The model includes hydraulic phenomenon but the pressure loss in the supply channel is not considered. The thermochemical model allows calculating the Gibbs free energy which is transformed into a chemical potential thanks to a transformer element TF on both anode and cathode. This theoretical potential is reduced by the activation and diffusion loses. They are represented by the Butler-Volmer and Fick's laws $N_{i}$ within a non-linear dissipative element RS (A resistance which generates a thermal flow).

$$
N_{i}=-c D_{i, j} \nabla X_{i}
$$

where $N_{i}$ is the mass flux of the specie $i, c$ is the total molar concentration, $D$ is the diffusion coefficient and $X_{i}$ is the mole fraction of specie $i$. The ohmic losses depend on the membrane hydration level, which is determined by an empirical relation. Moreover, the double layer phenomenon is modeled at each electrode by adding an energy storage element C. Finally all 
losses previously described generate heat that is injected into a thermal model. This model is composed of few association of $(\mathrm{R}, \mathrm{C})$ elements representing the thermal properties of the external sink, the terminal plates, the electrodes and the MEAs. The model has been validated with experimental data coming from a $200 \mathrm{~W}$ commercially available stack. The authors use the BG model to study the effects of high ripples current on the fuel cell.

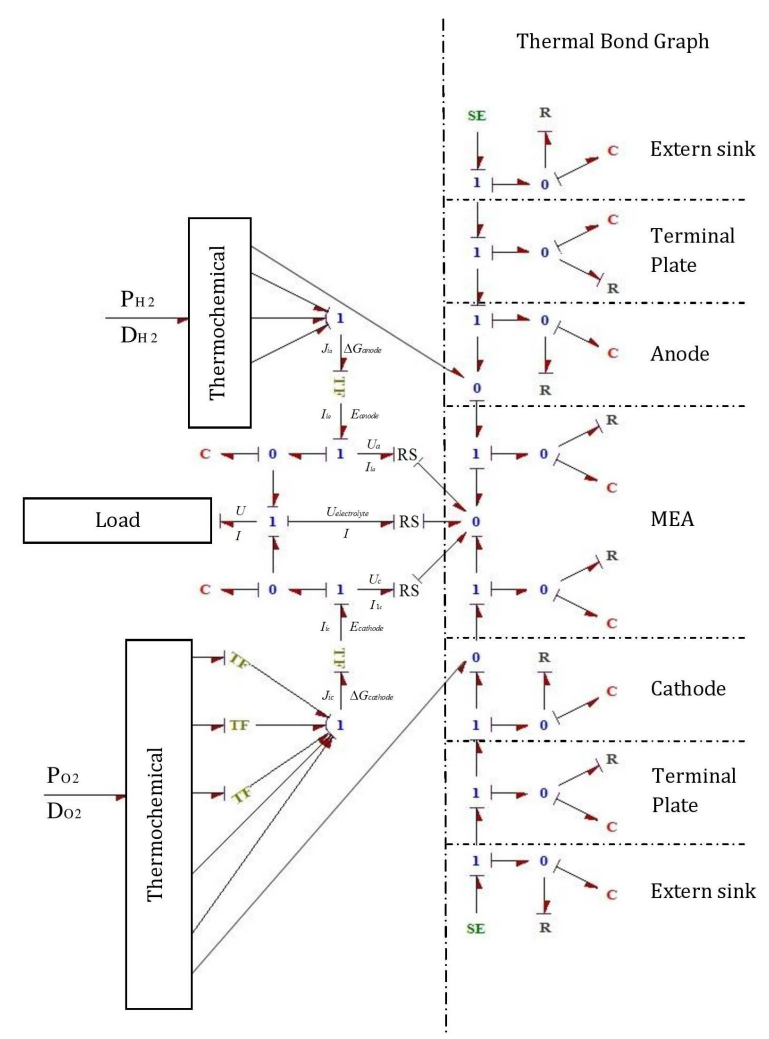

Fig. 7. Bond Graph of PEMFC [33]

Hung et al. [34] present a control-oriented model of a PEMFC based on a bond graph approach. It describes the fuel cell in two main subsystems: thermofluidic and electrochemical. The BG model of the first subsystem includes the mass flow rates of hydrogen, oxygen and water vapor at both anode and cathode. Moreover the back-diffusion and electro-osmotic drag effect are taken into account. This thermofluidic model is based on mass and energy conservation laws and is composed by an isotropic nozzle (4-port R element), a thermal accumulator (3-port C element) and a Gibbs free energy reactor (4-port IC element). The first element represents the difference of pressure and temperature between the up and downstream of every species which follow a nozzle-like law. The second element allows computing the instantaneous pressure and temperature at both electrodes. The last element computes the chemical potential of species depending on the operational conditions. This element is connected to the electrochemical part of the fuel cell model (refer to Fig. 8) where the chemical potential is transformed into an electrical potential with a transformer element TF (Faraday's law $\dot{n}$ ).

$$
\dot{n}_{i}=\frac{I N}{\alpha F}
$$

with $\dot{n}_{i}$ the molar flow of specie $i, I$ the load current, $N$ the number of cell of the stack, $\alpha$ the amount of exchanged electrons per mole and $F$ the Faraday constant. This theoretical voltage is diminished by the different losses, respectively activation, diffusion and ohmic ones. They are all represented by non-linear resistive elements. The two BG models are mutually connected and both exchange power with a thermal part (a single $\mathrm{C}$ element representing the heat capacity of the fuel cell). The BG formalism shows explicitly the state variable and allows the systematic generation of a state-space system. That model was simulated in order to study the transient responses of the voltage, pressure and temperature to a current step. The authors show that it is possible to predict accurately a transient fuel cell behavior with a low computational load. This bond graph model can be used to provide a feedback of the state-variable for a fuel cell controller in real-time.

McCain et al. [35] develop a discrete model of the Gas Diffusion Layer (GDL) of a fuel cell in the Bond Graph formalism (Fig. 9). The aim is to study the necessary spatial discretization of the GDL to predict accurately the flooding in a fuel cell 


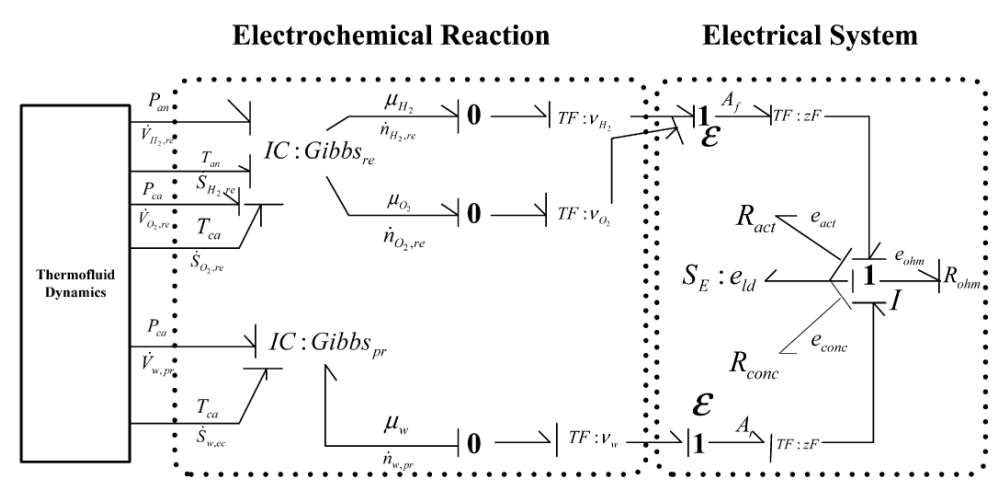

Fig. 8. Bond graph of PEMFC [34]

stack. This model considers water under liquid and vapor phase inside three GDL sections on the anode and cathode side. The gas concentration and the liquid phase water storage are represented by accumulation elements $\mathrm{C}$. The gas diffusion and the liquid water transport, because they cause friction within the GDL, are represented by passive elements R. One section of GDL is composed by a (R, C) association for each of the five following species: $\mathrm{H}_{2}, \mathrm{O}_{2}, \mathrm{~N}_{2}$, liquid and vapor water. The bond graph structural properties allow connecting in series several GDL sections. The authors could obtain a three layer discretized GDL. Because BG is an energy-based formalism, the authors used an energy-based reduction method named MORA to evaluate if the bond graph elements of the model are relevant and if they have to be kept in the model. That algorithm evaluates the activity of every elements of the model. It has shown that the oxygen and hydrogen gas flow require only one section of GDL to model accurately the behavior. Thus, the complexity of the model was reduced by $20 \%$ and it still predicts accurately the water dynamic within the cell.

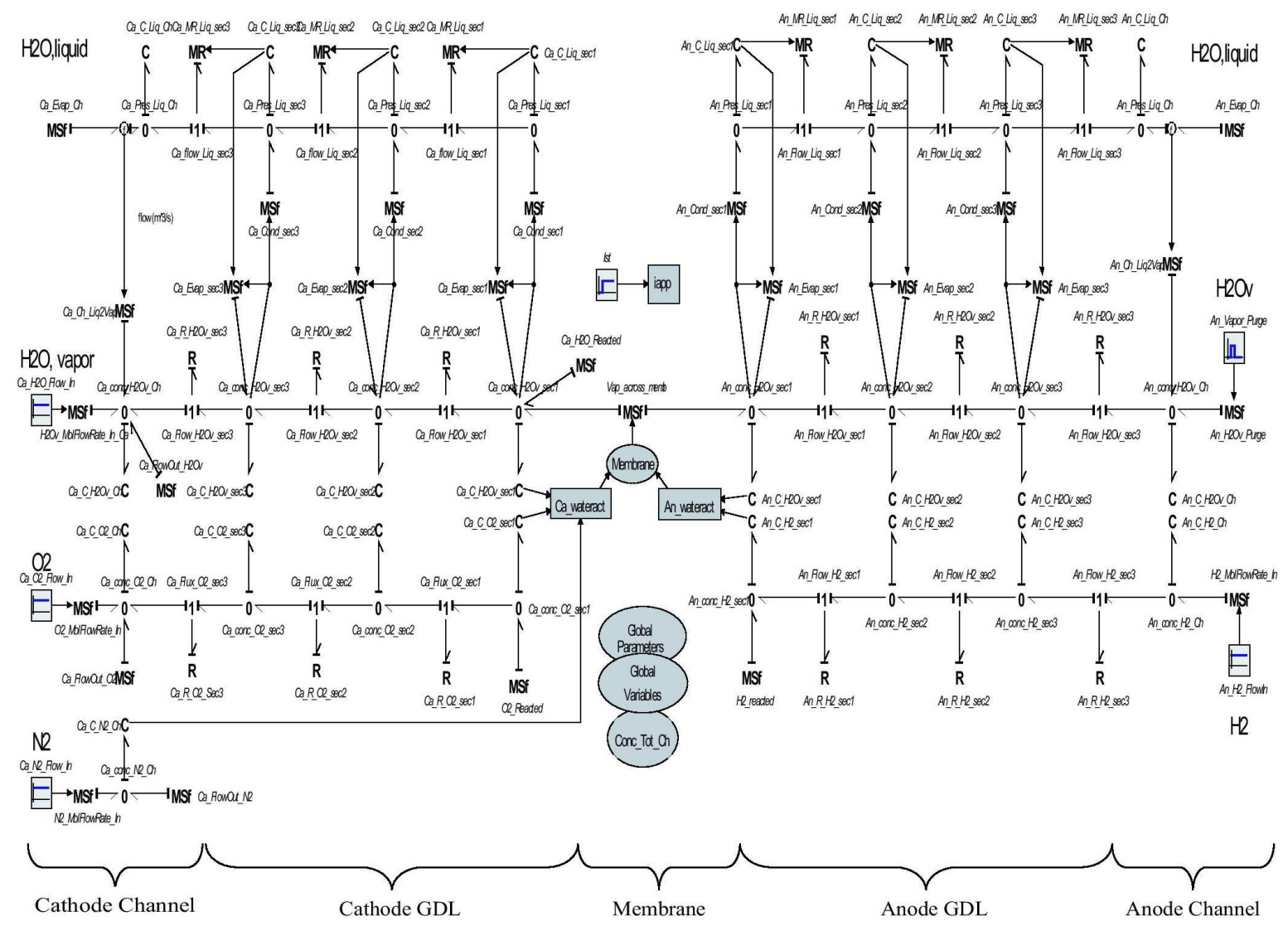

Fig. 9. Bond graph of PEMFC with a discrete GDL [35]

Chatti et al. [36] present a dynamic bond graph of a PEMFC stack. Like Saisset et al. [33], transformers allow the 
transition from the chemical to the electrical potential. The activation, diffusion and ohmic losses are also represented by non-linear resistive elements RS. But unlikely [33], that model (refer to Fig. 10) does not include any electrical or thermal dynamics. Moreover, a resistive element $\mathrm{R}$ represents the inlet hydrogen valve. The paper also presents a graphical representation emanating from the BG named Signed Bond Graph (SBG). The aim of this formalism is to conciliate a qualitative and quantitative reasoning for a diagnostic purpose. This PEMFC's SBG model allows the systematic generation of residuals and a diagnostic is performed. Using this formalism, the flooding and drying of the membrane can be isolated.

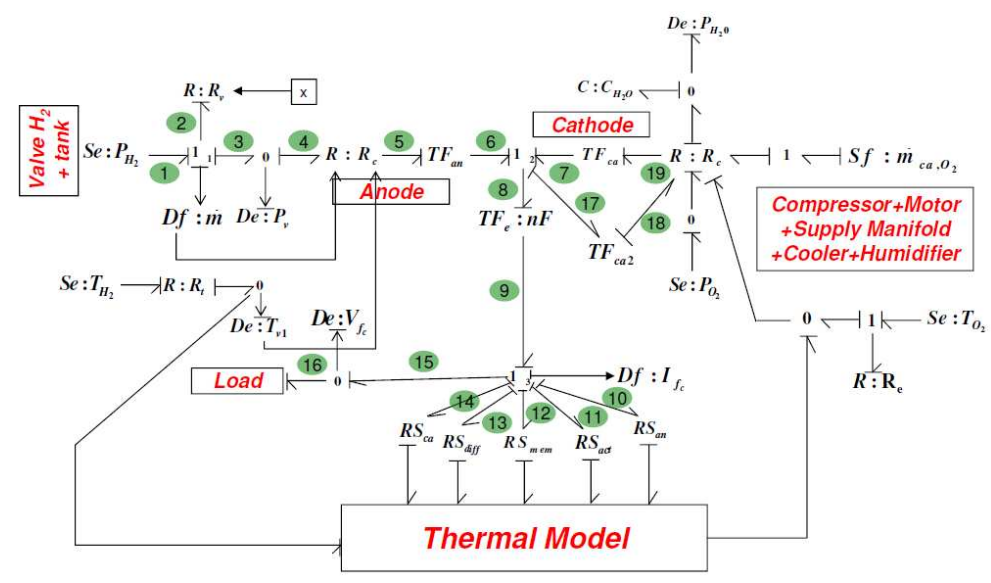

Fig. 10. Bond graph of PEMFC stack [36]

Schott et al. [37] present a fuel cell model based on the BG methodology. It consists of a semi-empirical electrochemical relation (not graphically represented), a hydraulic model composed by a one-dimension channel (each mesh is represented by a (R, C) association) and a dynamical electrode model (Fig. 11). It allows the computing of the species consumptions, the water production (under liquid and vapor phase) and the heat exchanges with the bipolar plates and the GDL. The paper proposes also a parameter identification to fit the model to experimental data. In [38], the same authors propose models for the condenser and output valve in the bond graph formalism. Because of the BG structural properties, it is possible to replace a sub-system to fit the granularity needed. This is why Gerard et al. [39], use the global model previously presented, but the channels and the MEA are now described in two-dimension, where every mesh is a RC association. This model allows studying the local impact of the fuel and oxygen starvation.

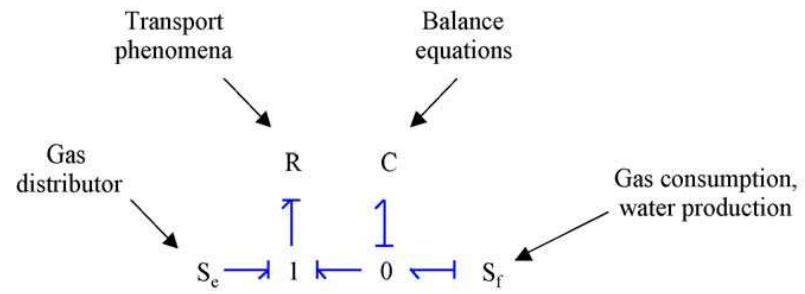

Fig. 11. Bond Graph model of the hydraulic phenomenon in an electrode [37]

Benchouia et al. [40] show a Bond Graph model of a fuel cell system. It includes a PEMFC, and a battery that are connected to a bus using DC-DC converters (boost and buck respectively). The fuel cell model is able to compute the stack voltage depending on the load current and flow rate of gas (pure $\mathrm{H}_{2}$ and $\mathrm{O}_{2}$ ). Moreover, the ideal voltage is defined using the Nernst equation and so is dependent on the stack temperature and pressure. The hydraulic field allows to estimate the partial pressure using the molar flow of consumed gas (Faraday's law) and the input flow of gas through the valve. One can note that the temperature is considered constant and that the model does not contain any hydraulic dynamic. Nevertheless, the double layer effect is modeled (not graphically represented). The authors simulate the overall system on the dedicated software 20-Sim and on Matlab-Simulink.

Bressel et al. [41] present a dynamic BG model (see Fig. 12) that describes the pressure drops between the anode and the cathode through a trio of elements R-C-R which allows to estimate the partial pressure on the catalyst sites. The open circuit voltage is described by means of an empirical relationship within a RS element. This voltage is corrected by the Nernst law as a function of the partial pressures (an RS element showing graphically the coupling between the electrical and 
hydraulic domain). Activation, ohmic and concentration losses are combined in one element RS. In addition, the electrical dynamics is represented by a pair of element $\mathrm{RC}$, which account for the double layer capacitance in parallel to the charge transfer resistance. The hydraulic, chemical and electrical subsystems produce heat which is evacuated through a cooling circuit. This thermal model (RC) is able to calculate the temperature of the fuel cell based on the flow rate and temperature of the cooling water. The authors propose a methodology for parameters identification of the model which is then validated with experimental data from an 8-cells PEMFC.

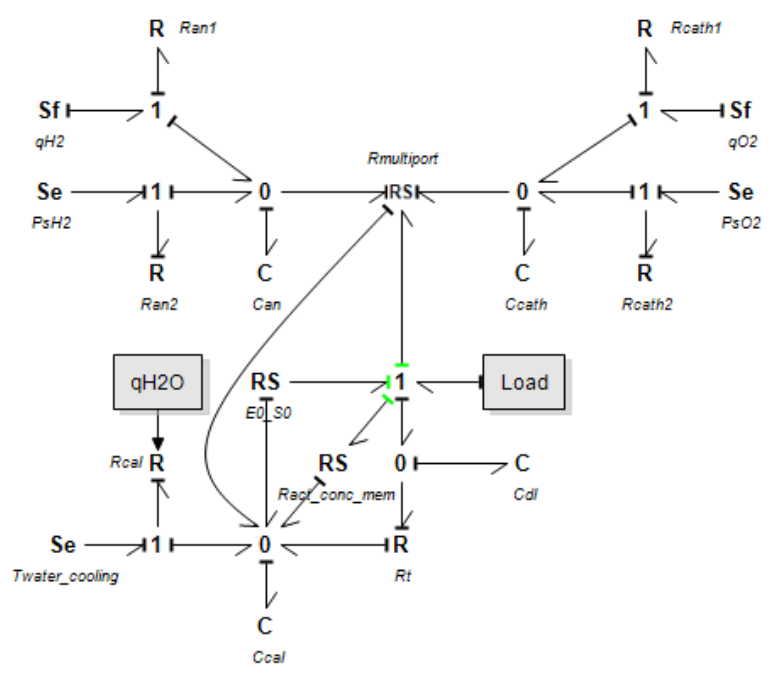

Fig. 12. Bond Graph model of a PEMFC stack [41]

More recently, Mzoughi et al. [42] show a separate electrodes model of PEMFC in the BG formalism (see Fig. 13). It shows on both anode and cathode the transformation from the hydraulic field (constant pressure) to electro-chemical field, the activation and concentration losses (through a RS element) and the double layer effect. Both electrodes are connected using a junction-1 where the ohmic loss (RS element) is removed from the computed overall voltage. This subsystem creates heat that is send to a thermal model. This subsystem is composed of a $\mathrm{C}$ element for the heat accumulation, and two $\mathrm{R}$ elements (showing the losses by conduction and convection). One can note that the model is able to predict the quantity of water produce, nevertheless the membrane conductivity is not a function of the water content. This model is then used to develop control laws for a solenoid valve and a compressor (anode and cathode side respectively).

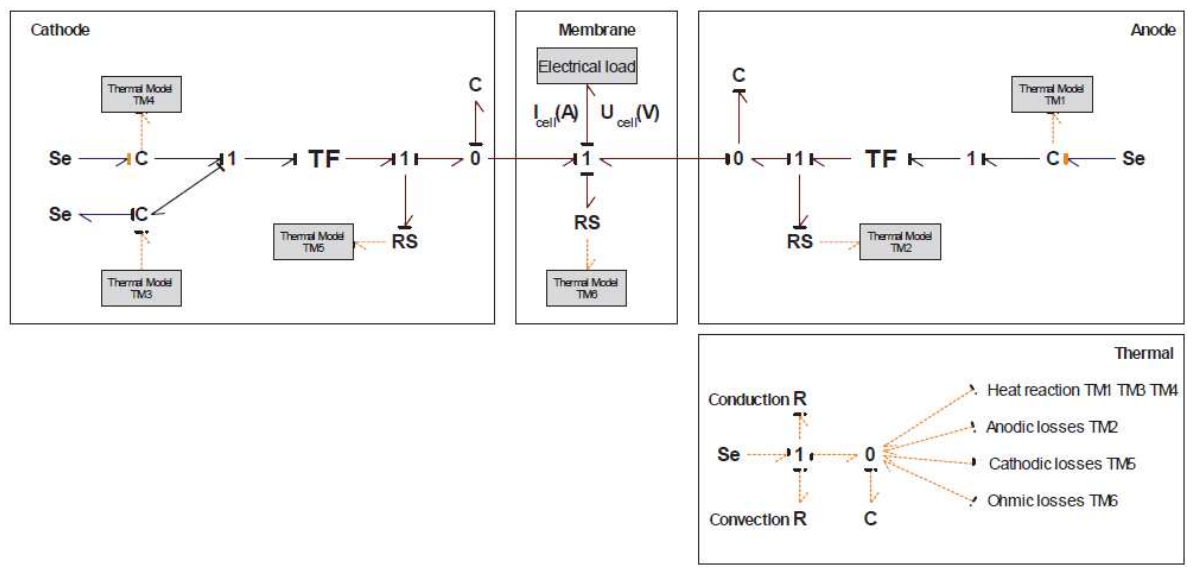

Fig. 13. Bond Graph model of a single cell [42]

One can notice that Bond Graph models have a wide field of application (study of internal parameters, design, control and diagnostic). Moreover, the formalism allows to model multi-physical phenomena in several dimension. A summary of those models can be found in Tab. 3 . 


\subsection{Causal Ordering Graph (COG) model of Fuel Cell}

Francois et al. [43] present a COG representation of a PEM fuel cell system. This model is connected also to a wind turbine, an ultra capacitor and an electrolyzer. Those elements are connected to the grid through a DC bus with an inverter. The PEM fuel cell model (refer to Fig. 14) includes a hydraulic part. A causal element computes the pressure inside of the two electrodes depending on the incoming molar gas flow and the consumed gas in R7 and R8 (Faraday's law). The anode and cathode causal processors inject the pressures in a rigid processor which calculates the reversible electrical potential through the Nernst law in R1. The activation loss is an empirical equation depending on the temperature, current and the concentration of dissolved oxygen at the gas/liquid interface (Henry's law). The activation and ohmic losses are represented by the acausal elements R3 and R6. Moreover, the model is dynamical because of the effect of double charge layer (represented by a causal processor in series with the $\mathrm{R} 5$ processor). The model also takes into account the thermal phenomena for computing the temperature. The authors show a simulation of the global system with a particular wind profile. That model allows a macroscopic energy management of a hybrid power generation system.

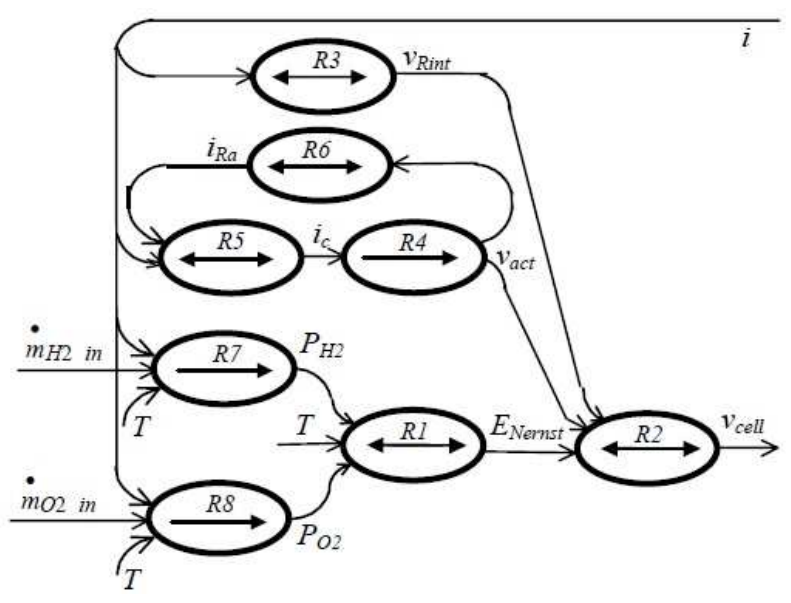

Fig. 14. Dynamic model of a PEMFC in COG formalism [43]

\subsection{Energetic Macroscopic Representation (EMR) model of Fuel Cell}

Chrenko et al. [44] present an Energetic Macroscopic Representation of a PEMFC. The hydraulic part is taken into account in the cathode side by a dynamical equation Pcath $=\frac{1}{C_{\text {cath }}} \int\left(\dot{V}_{\text {air Out }}-\dot{V}_{\text {airCath }}\right)$ and represented by an accumulation element. The output pressure is connected to a distribution element which computes the air flow $\dot{V}_{\text {airCath }}$ depending on the oxygen, water and input air supply. For both electrodes, multiphysical coupling elements transform the volumetric flow to a molar flow following the ideal gas law $P V=n R T$. Those molar flows are injected in a monophysical distribution element to compute the Gibbs free energy which is converted into a voltage through a conversion element. This theoretical voltage is corrected in pressure and temperature within a coupling element. Moreover, this element also includes the activation, ohmic and concentration overpotentials through a semi empirical equation. All the previous elements are coupled with a single order thermal model (accumulation element). That representation (refer to Fig. 15) also includes a model of the air supply with its associated Maximum Control Structure (MCS). The authors validate this model and control using experimental data from a commercially available $1,2 \mathrm{~kW}$ fuel cell stack.

Hissel et al. [30] describe a separated electrodes PEM fuel cell representation with the EMR formalism. Unlikely [44], this model includes dynamical hydraulic equations with pressure losses on both anode and cathode which are represented by a converter in the input and a converter associated with an accumulation element on the output. Both streams allow computing the partial pressure on the MEA through a coupling element. The electrical potential $E 0$ is computed with an empirical equation within a converter. The partial pressures and this last potential are injected in a multiphysical coupling element to obtain the Nernst potential. This voltage is diminished by the activation (Tafel's equation), concentration and ohmic losses expressed in a coupling element. Moreover, some electrical dynamic is represented by an accumulative element showing the double layer effect. The chemical reactions and the electrical losses produce a flow of entropy that is evacuated by a water cooling system. This thermal dynamical model requires the volumetric flow and the temperature of the cooling water and it is able to compute the temperature of the fuel cell stack (represented by a controlled conversion block associated with an accumulation element). The whole model is shown on Fig. 16 and had been validated on a commercially available 20 cells stack 


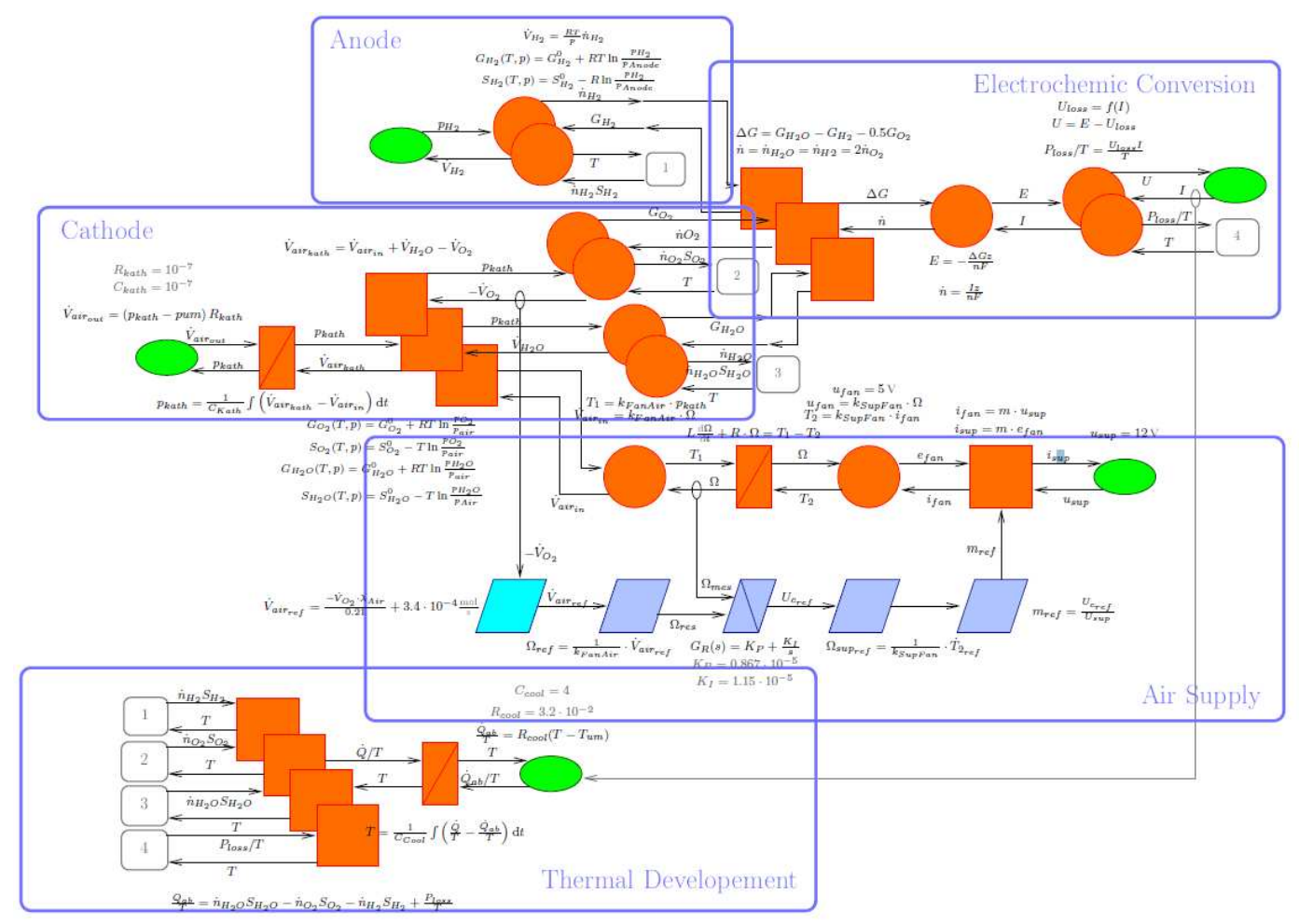

Fig. 15. EMR of a PEMFC and its associated air supply [44]

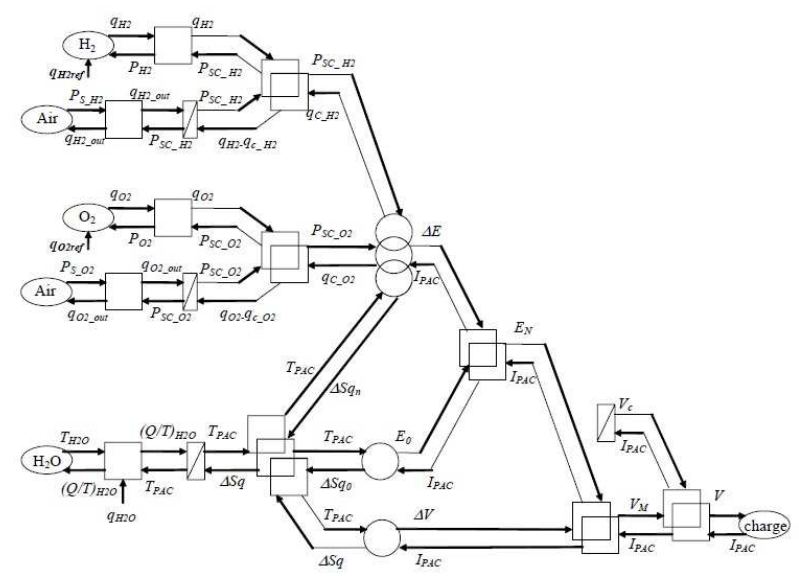

Fig. 16. EMR of PEMFC [30]

Boulon et al. [45] show the EMR model of the PEMFC's ancillaries. Using previous works [30], they design a fuel cell power generation device representation. It includes a model of the air compressor (constituted by a vane supercharger, a DC motor and its power electronics), the cooling circuit and the power converter connected to a DC bus (refer to Fig. 17). The authors validate by experience the fuel cell and compressor models separately. The same author presents in [26] the Maximal and Practical Control Structure (MCS and PCS) applied to a PEMFC. The aim is to control the fuel cell voltage by tuning two variables: the input gas flows of oxygen and hydrogen. The first step is the design of the MCS by inversion of the EMR model. Then the unrealistic measurements are replaced by an estimation (e.g. local partial pressures) to lead to a practical control structure. As a drawback, those control structures impose the reference values to stay inside of the validity range of the model. This paper finally shows the voltage reachable by the system considering the assumptions and the dynamic behavior of the PEMFC by simulation.

Solano-Martinez et al. [46] propose one of the numerous applications of the EMR to a hybrid electric vehicle. The originality of this paper is to include within the EMR formalism the overall energy management strategy. The global system includes a PEMFC, a compressor, batteries, and a super-capacitor system. All those elements are interconnected via a DC bus (Fig. 18). The MSC and PSC are then developed for the control of the PEMFC. The paper highlights the required measurements for the two strategies and proposes simulation results when a Normalized European Driving Cycle (NEDC) 


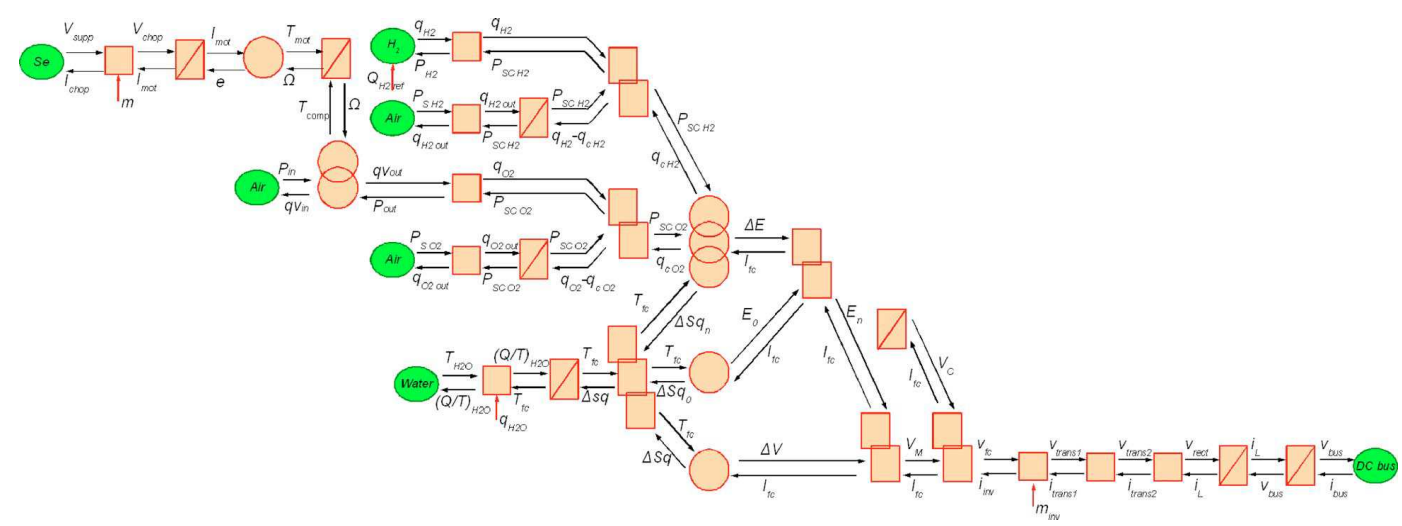

Fig. 17. EMR of a PEMFC and its auxilaries [45]

is used. This fuel cell model is a simplified version of Hissel et al. [30]. Indeed the electrical and thermal dynamics were neglected. The reader is invited to refer to Baert et al. [47] and Ettihir et al. [48] for other applications of the EMR to a hybrid vehicle.

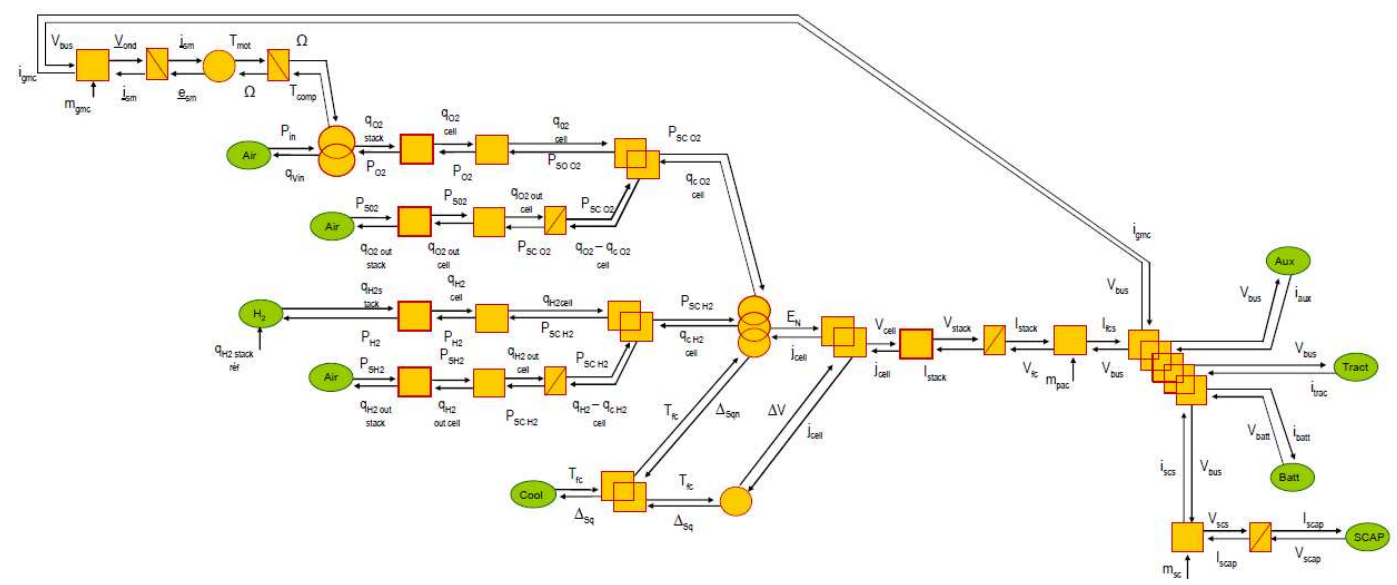

Fig. 18. EMR of a hybrid electric vehicle [46]

Gauchia et al. [49] propose a simple PEMFC model in the EMR formalism. This model (refer to Fig. 19) is represented by a source element whose voltage depend on the input current and on the operational conditions. The intrinsic model is based on an electrical equivalent and includes the ohmic loss and the double layer capacitance. It has to be notice that the thermal and hydraulic phenomenon of the fuel cell are not taken into account. Moreover, the paper presents an energetic macroscopic representation of a battery, supercapacitor, and the mechanical part of a vehicle. All those elements are connected together using coupling elements to form a hybrid electrical vehicle model. Thanks to the maximum control structure, the authors are able to develop a command strategy for this multi-sources system.

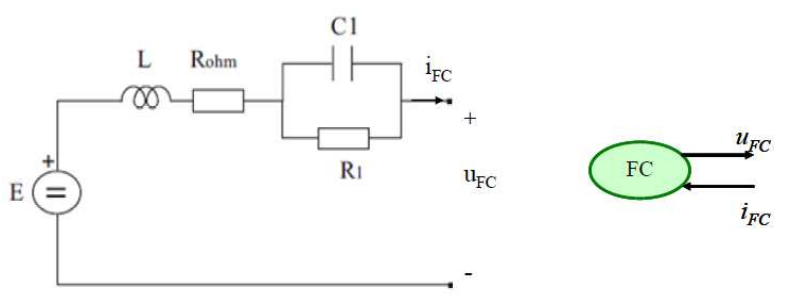

Fig. 19. EEC of a PEMFC and its EMR equivalent [49]

EMR models of PEMFC are mainly used for a control and energy management purpose. Indeed, this formalism allows to model multi-physical systems (with an energetic representation) and to develop a control scheme based on model inversion. 
To keep a systemic philosophy, the models are often macroscopic and so does not discretise the phenomenon. All the models and their comparison can be found in Tab. 3.

\subsection{Equivalent Electrical Circuit (EEC) model of Fuel Cell}

Boscaino et al. [50] present an empirical fuel cell model. Its objective is to represent the steady-state with diodes and voltage sources (refer to Fig. 20). Moreover, the transient behavior is modeled by three RC networks in order to fit the response to a current step. That model does not bring a physical meaning of the fuel cell phenomenon.

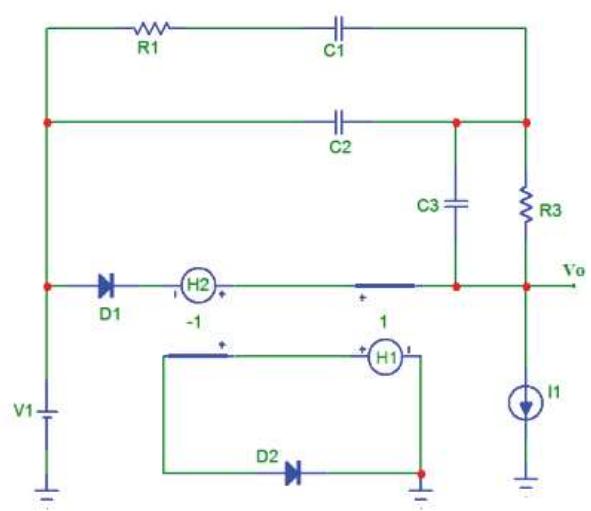

Fig. 20. EEC of a PEMFC [50]

Wingelaar et al. [51] show three PEMFC models: a steady-state, a large signal and a small signal model. The steady-state model includes the reversible voltage, the ohmic, activation and concentration losses. The large signal model (refer to Fig. 21) is composed by a voltage source in series with a double layer capacitor in combination with a parallel and a series resistor. The small signal model adds to the previous model an impedance $\mathrm{Z}$ in parallel of the double layer capacitor representing the adsorption reaction. The parameters of those three models have been identified using respectively a polarization curve, the interrupted current method and an impedance spectroscopy.

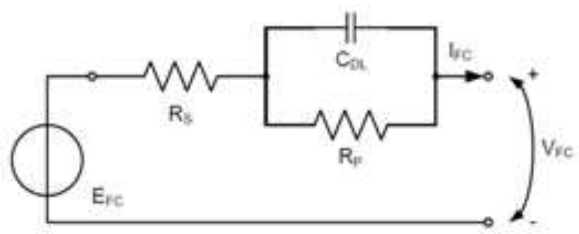

Fig. 21. Large signal EEC of a PEMFC [51]

Famouri et al. [52] develop a dynamical equivalent circuit model of a fuel cell taking into account water vapor. It is constituted by five sub-circuits representing respectively the cathode and anode humidifier, the conservation of oxygen, hydrogen and water. The main fuel cell model consists in three nonlinear current controlled voltage sources (Nernst, electrochemical over-potential, and diffusion over-potential), a capacitor (double layer effect), and a stack resistance (Fig. 22). It has to be noticed that the membrane resistance does not depend on the water content.

Fontes et al. [53] present a dynamical large signal circuit model of a PEMFC. It includes the reversible voltage (voltage source), ohmic losses (resistance), the activation (non-linear current source) and double layer phenomenon. The gas diffusion phenomena have been modeled in two parts: in the GDL and in the activation layer with non-linear current sources as presented in Fig. 23. Moreover, two capacitive elements are added for representing the dynamic of gas diffusion. The model's parameters are then identified using a least-square optimization method on a low frequency current sweeps input signal. The aim of this model is to study the interactions between PEMFC stacks and static converters. Experimental and simulation results show the effect of the connection of a fuel cell with a buck chopper and a single phase inverter.

Wang et al. [54] present a dynamical model of a PEMFC using electrical equivalent circuits. The gas diffusion in the electrodes is described using the Stefan-Maxwell law and is used to know the effective partial pressure (not graphically represented). The Nernst equation allows computing the reversible voltage. It is constituted by a voltage source and two controlled voltage sources (to correct the theoretical potential in pressure and temperature); the activation overpotential is 


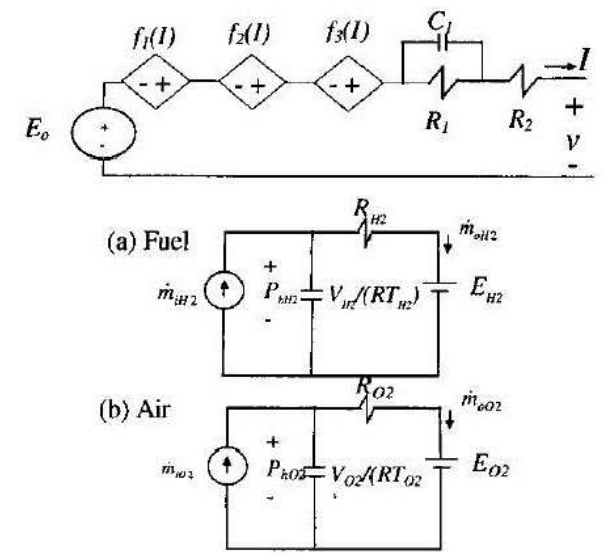

Fig. 22. EEC of a PEMFC, fuel (a) and air (b) humidifiers circuit [52]

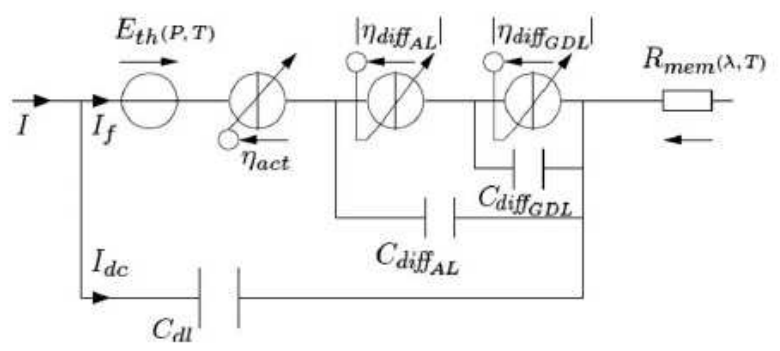

Fig. 23. Large signal EEC model of a PEMFC [53]

represented by a series association of voltage sources with temperature and current dependent resistors. The ohmic and concentration voltage drops are added to the model using temperature and current dependent resistors. Moreover, the double layer (capacitor) and the thermal phenomenon are implemented as presented in Fig. 24. The last one is represented by a RC association, where $\mathrm{R}$ stands for a thermal resistance due to the convection and $\mathrm{C}$ for a heat capacity. It is able to compute the fuel cell temperature which is injected in the temperature dependent resistors of the model. The authors validate the steady-state and transient by comparing the model (under Pspice and Matlab/Simulink) to experimental data.

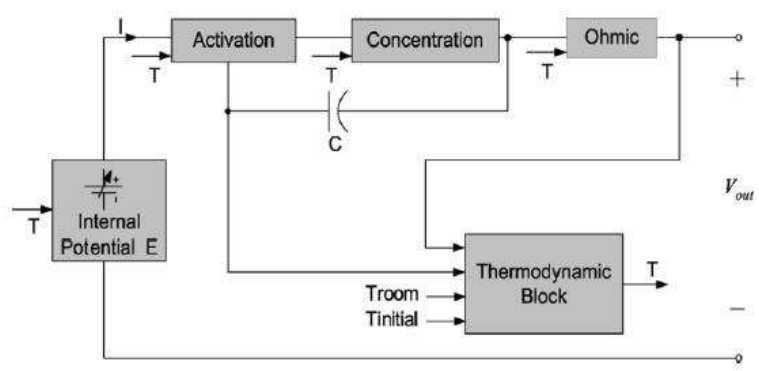

Fig. 24. Pspice scheme of a PEMFC [54]

Becherif et al. [55] develop a separated electrodes electrical equivalent model of the pneumatics and fluidics phenomenon in a fuel cell. The model (refer to Fig. 25) includes the diffusion of water and nitrogen across the membrane as well as the reverse electro-osmotic drag (represented by resistors because the degree of diffusion depends on the pressure differences between the two electrodes). On both electrodes, the water condensation is modeled by Zener diodes and the hydraulic dynamic (with pressure losses) by an association of two resistors and one capacitor. Simulations are conducted to validate this model on a 20-cell PEM fuel cell stack.

Noiying et al. [56] present an Electrical equivalent model of a PEMFC with a spatial description of mass transport. It includes a discrete GDL for anode and cathode. At the anode, each of the ten layers is composed by two coupled sub-circuits (three for the cathode) that describe the diffusion of gas mixture. The partial pressure in a layer is represented by a coupled voltage source and the molar flow of each specie by coupled resistances. The dynamic of the fluid is added to the model 


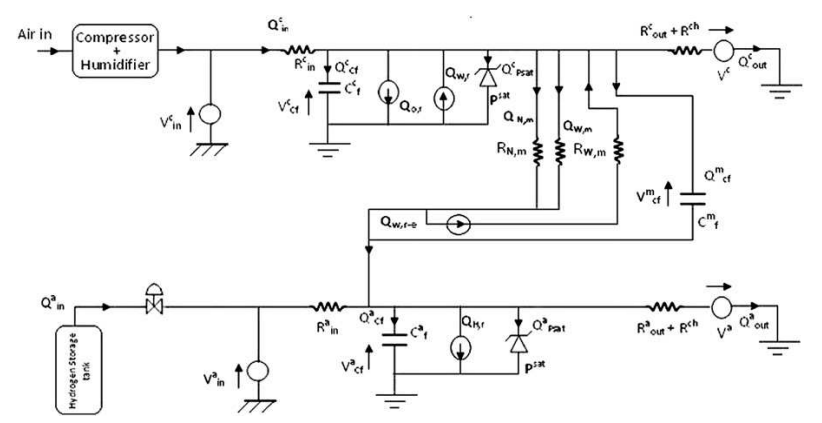

Fig. 25. EEC of the pneumatics and fluidics phenomenon in a PEMFC [55]

thanks to a capacitor. The input molar flows (current source) or input partial pressure (voltage source) can impose their value depending on the over-stoichiometry. That boundary condition is represented by a diode. The output of those subcircuits allows computing the pressure losses, and the activation over-potential depending on the current reference and faradic currents. The membrane is also discretized in ten layers where each spatially describes the electro-osmotic drag (voltage source), the back-diffusion, the water content and so the ionic losses (the resistivity of the membrane is water dependent). The global model (refer to Fig. 26) includes the transport models previously presented that allow calculating the electrodes potentials and over-voltages. All those voltage drops are represented by controlled voltage sources. Finally, the double layer effect is added with anodic and cathodic capacitors. Experiments are carried out to validate this one dimensional model.

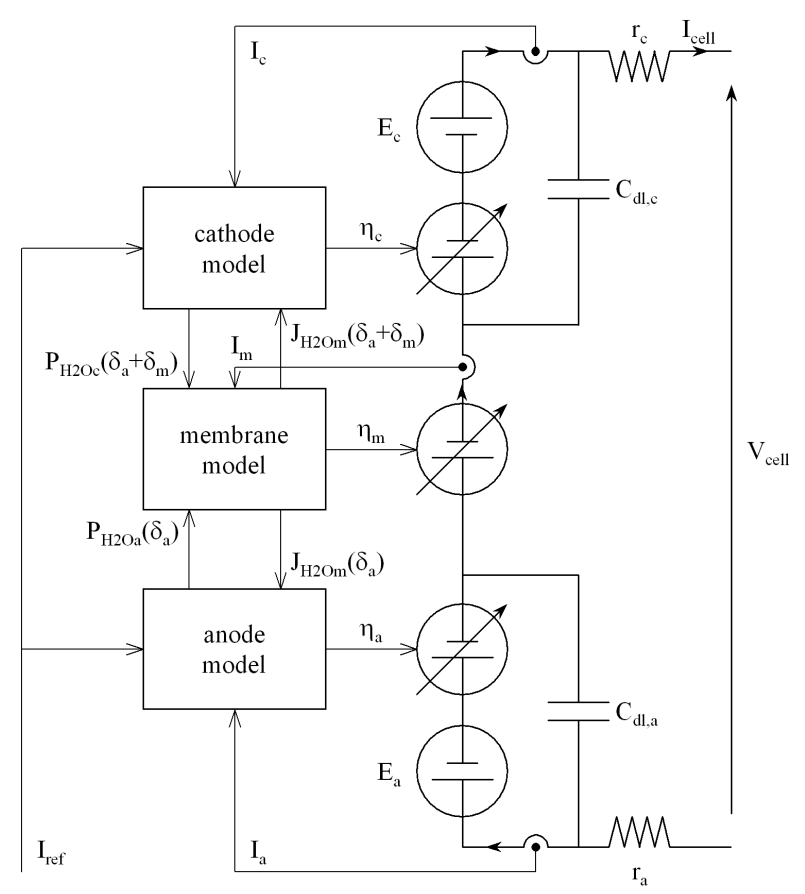

Fig. 26. EEC of a PEMFC [56]

De Beer et al. [57] present an equivalent electrical circuit of a fuel cell which including the effect of CO poisoning. The aim is to use this model for a rapid fault diagnostic. In steady-state, a diode in series with a resistor represents the activation and ohmic losses. Because those phenomena are strongly influenced by the CO poisoning, the authors propose to add a diode and resistor to the global model to show the effect of this poisoning (Fig. 27). The circuit parameters can be easily monitored and can be used for CO poisoning diagnostic. Some experiments have been conducted in order to show the influence of the poisoning on the steady-state.

Hernandez et al. [27] propose a model of PEMFC for fault diagnostic purpose. This model includes the hydraulic dynamics with pressure losses (resistances and capacitor association as in Hissel et al. [30]) and the humidifier system (similar to the hydraulic model but including a current source representing the water vapor flow and a Zenner diode for the vapor saturation pressure in parallel with the capacitor). The overall hydraulic equivalent circuit is composed by one sub-circuit for each specie: oxygen (only on cathode), hydrogen (only on anode), water vapor and nitrogen (refer to Fig. 28). 


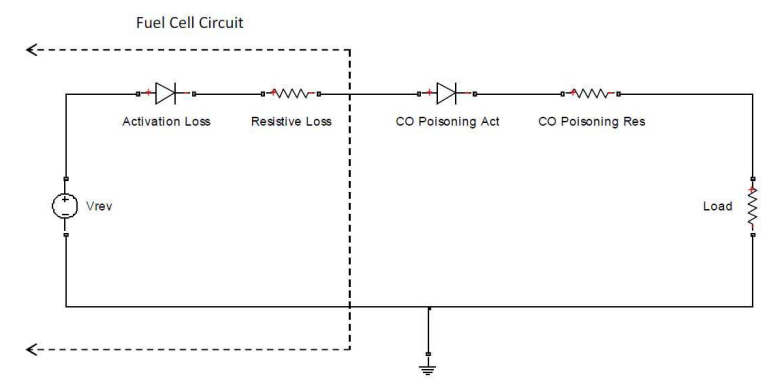

Fig. 27. EEC of a PEMFC for CO poisoning diagnosis purpose [57]

For the two last ones, a resistance connects the anodic and cathodic part. It represents the diffusion possibility of nitrogen and water vapor through the membrane. The model includes the Nernst equation to evaluate the open circuit voltage which is reduced by the activation (Tafel's equation), concentration and ohmic over-potentials that are not graphically shown. The circuit modeling approach allows here the easy generation of residuals leading to a diagnostic. The authors propose to monitor the cathode pressure drop to evaluate the flooding with some experimental validation.

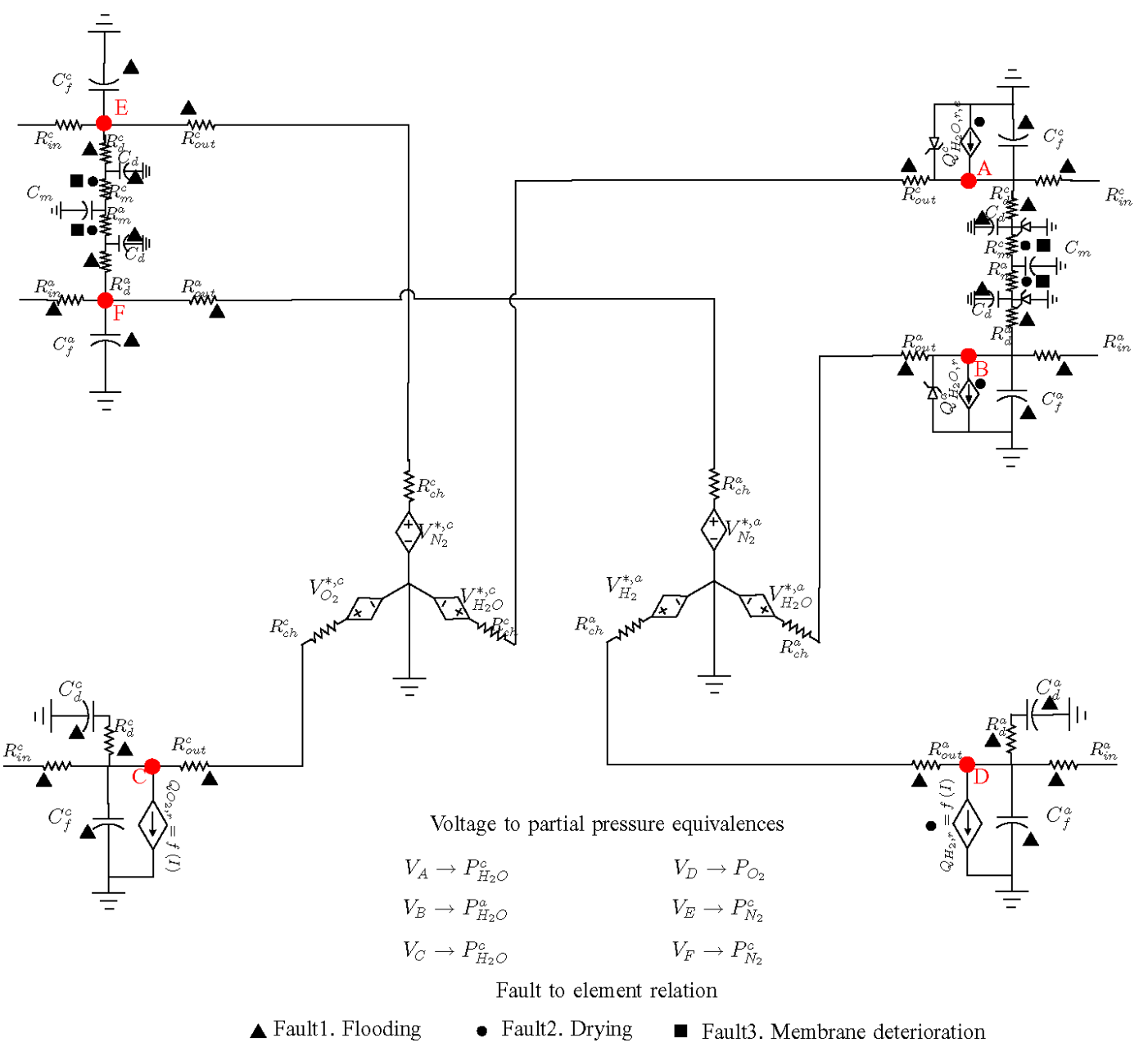

Fig. 28. EEC of a PEMFC for fault diagnosis purpose [27]

The EEC is a formalism mastered by many, contributing to its deployment in the scientific field. One can notice that the developed models do not include thermal field in general and the main modeled dynamics are electrical. Nevertheless, this formalism is successfully used for the simulation and diagnostic of PEMFC stack as summarized in Tab. 3. 


\section{Synthesis}

In the previous sections, a survey of graphical representation for modeling has been presented. The advantages and drawbacks of the considered formalisms have been shown and are resumed in Tab. 2. This table details for each formalism: the possibility to model multi-physical systems, the causality, if the used variables are energetic, if the system is represented functionally or structurally, the command structure, the possibilities for system diagnostic and for the association of models, finally the dedicated software are given.

\begin{tabular}{ccccc}
\hline & BG & EMR & COG & EEC \\
\hline Multi-domain & yes & yes & yes & by analogy \\
Causality & integral / differential & integral & integral & integral \\
Energetic & yes & yes & no & implicit \\
Functional / Structural & structural & functional & functional & functional \\
Command & transfer function & model inversion & model inversion & electric approach \\
Diagnostic & yes [16] & not yet & no & yes [57] \\
Association of different models & yes & yes & yes & no \\
Dedicated software & 20-Sim & Matlab Simulink & Matlab Simulink & Pspice, Matlab toolbox etc.
\end{tabular}

Table 2. Comparison of graphical representations

A review on PEMFC models using those graphical representations has been also presented and is resumed on Tab. 3. It shows for every considered model: the system boundary, the purpose, the spatial dimension, if the model is able to produce a polarization curve and some transient responses, if the thermal and hydraulic phenomenon are described, and finally if the model takes into account the water (liquid and vapor).

\section{Conclusion}

A classification of graphical representation to model systems has been proposed including the bond graph, the causal ordering graph, the energetic macroscopic representation and electrical equivalent circuit. It is important to notice that most of those tools does not propose classical automatic analyzing tools such as observability or controllability. For a deeper study, the designer must consider the analytical relations. Nevertheless, graphical representations are useful to study a whole system in a macroscopic way showing the exchange of power between elements.

Then, a survey on those representation applied to a proton exchange membrane fuel cell system has been shown. Depending on the studied phenomenon, the model will propose a hydraulic or thermal part and take into account water. One can notice that the BG allows the design, the control and the diagnostic of a PEMFC. The EMR is mainly use for a control and energy management purpose. EEC is used for simulation and diagnostic purposes. Therefore, the designer chooses the graphical representation and the granularity depending on the objective of the model.

The graphical representation allows the user to add more functionality to his model connecting new subsystems or to include it in a bigger system. The exchange of power is mostly explicit and the coupling is shown. The usefulness of this approach applied to a Fuel Cell has been demonstrated.

\section{Acknowledgements}

This work was supported by the French national project ANR PROPICE (ANR-12-PRGE-0001).

\section{References}

[1] Barbir, F., 2012. PEM fuel cells theory and practice. Academic Press.

[2] Jouin, M., Gouriveau, R., Hissel, D., Péra, M. C., and Zerhouni, N., 2013. "Prognostics and health management of pemfc - state of the art and remaining challenges". International Journal of Hydrogen Energy.

[3] Biyikoglu, A., 2005. "Review of proton exchange membrane fuel cell models". International Journal of Hydrogen Energy, 30, pp. 1181-1212. 


\begin{tabular}{|c|c|c|c|c|c|c|c|c|}
\hline Models & System boundary & Purpose & Dimension & Polarization & Dynamics & Thermal & Hydraulic & Water \\
\hline \multicolumn{9}{|l|}{$\overline{B G}$} \\
\hline - Peraza & stack & simulation & 0 & $\checkmark$ & & & & \\
\hline - Rabih & channel & designing channel dimension & 0 & & $\checkmark$ & & $\checkmark$ & \\
\hline - Saisset & stack & effects of ripple curents & 0 & $\checkmark$ & $\checkmark$ & $\checkmark$ & $\checkmark$ & $\checkmark$ \\
\hline - Hung & stack & state feedback control & 0 & $\checkmark$ & $\checkmark$ & $\checkmark$ & $\checkmark$ & $\checkmark$ \\
\hline - Mc Cain & GDL & model complexity reduction & 1 & $\checkmark$ & $\checkmark$ & & $\checkmark$ & $\checkmark$ \\
\hline - Chatti & stack & diagnostic of flooding and drying & 0 & $\checkmark$ & $\checkmark$ & $\checkmark$ & $\checkmark$ & \\
\hline - Schott & stack,condenser,and valve & simulation & 1 & $\checkmark$ & $\checkmark$ & $\checkmark$ & $\checkmark$ & $\checkmark$ \\
\hline - Gerard & stack & study of fuel and oxygen starvation & 2 & $\checkmark$ & $\checkmark$ & $\checkmark$ & $\checkmark$ & $\checkmark$ \\
\hline - Benchouia & system: power generator & simulation & 0 & $\checkmark$ & $\checkmark$ & & $\checkmark$ & $\checkmark$ \\
\hline - Bressel & stack & simulation & 0 & $\checkmark$ & $\checkmark$ & $\checkmark$ & $\checkmark$ & \\
\hline - Mzoughi & stack, compressor, valve & control of $\mathrm{O}_{2}$ and $\mathrm{H}_{2}$ flow & 0 & $\checkmark$ & $\checkmark$ & $\checkmark$ & $\checkmark$ & $\checkmark$ \\
\hline \multicolumn{9}{|c|}{ 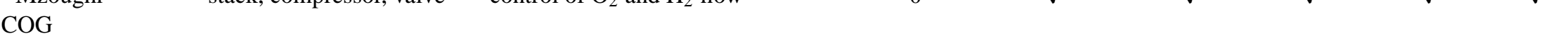 } \\
\hline - Francois & system: power generator & simulation & 0 & $\checkmark$ & $\checkmark$ & $\checkmark$ & $\checkmark$ & \\
\hline \multicolumn{9}{|l|}{ EMR } \\
\hline - Chrenko & stack, air supply & control of air supply & 0 & $\checkmark$ & $\checkmark$ & $\checkmark$ & $\checkmark$ & \\
\hline - Hissel & stack, cooling & simulation & 0 & $\checkmark$ & $\checkmark$ & $\checkmark$ & $\checkmark$ & \\
\hline - Boulon & system: power generator & control of a fuel cell & 0 & $\checkmark$ & $\checkmark$ & $\checkmark$ & $\checkmark$ & \\
\hline - Solano-Martinez & system: vehicule & energy management & 0 & $\checkmark$ & $\checkmark$ & $\checkmark$ & $\checkmark$ & \\
\hline - Gauchia & system: vehicule & energy management & 0 & & $\checkmark$ & & & \\
\hline \multicolumn{9}{|l|}{ EEC } \\
\hline - Boscaino & stack & simulation & 0 & $\checkmark$ & $\checkmark$ & & & \\
\hline - Wingelaar & stack & simulation & 0 & $\checkmark$ & $\checkmark$ & & & \\
\hline - Famouri & stack & simulation & 0 & $\checkmark$ & $\checkmark$ & & $\checkmark$ & $\checkmark$ \\
\hline - Fontes & stack & interactions with static converters & 0 & $\checkmark$ & $\checkmark$ & & & \\
\hline - Wang & stack & simulation & 0 & $\checkmark$ & $\checkmark$ & $\checkmark$ & $\checkmark$ & \\
\hline - Becherif & stack & simulation & 0 & & $\checkmark$ & & $\checkmark$ & $\checkmark$ \\
\hline - Noiying & stack & simulation & 1 & $\checkmark$ & $\checkmark$ & & & $\checkmark$ \\
\hline - De Beer & stack & diagnostic of $\mathrm{CO}$ poisoning & 0 & $\checkmark$ & & & & \\
\hline - Hernandez & stack, humidifier & diagnostic of flooding & 0 & $\checkmark$ & $\checkmark$ & & $\checkmark$ & $\checkmark$ \\
\hline
\end{tabular}

Table 3. Resume of the characteristics of the graphical representations of PEMFC 
[4] Springer, T., Zawodzinski, T., and Gottesfeld, S., 1991. "Polymer electrolyte fuel cell model". J. Electrochem. Soc, 138, pp. 2334-2342.

[5] Amphlett, J. C., Baumert, R. M., Mann, R. F., Peppley, B. A., and Roberge, P. R., 1995. "Performance modeling of the ballard mark iv solid polymer electrolyte fuel cell i. mechanistic model development". J. Electrochem. Soc, 142, pp. $1-10$.

[6] Costamagna, P., 2001. "Transport phenomena in polymeric membrane fuel cells". ChemEng Sci, 56, pp. $323-332$.

[7] Lee, J., Lalk, T., and Appleby, A., 1998. "Modeling electrochemical performance in large scale proton exchange membrane fuel cell stacks". Journal of Power Sources, 70, pp. 258-268.

[8] Hontanon, E., Escudero, M., Bautista, C., Garcia-Ybarra, P., and Daza, L., 2000. "Optimisation of flow-field in polymer electrolyte membrane fuel cells using computational fluid dynamics techniques”. Journal of Power, 86, pp. $363-368$.

[9] Barre, P. J., Bouscayrol, A., Delarue, P., Dumetz, E., Giraud, F., Hautier, J. P., Kestelyn, X., B.Lemaire-Semail, and E.Semail, 2006. "Inversion-based control of electromechanical systems using causal graphical descriptions". IEEEIECON'06.

[10] Djeziri, M. A., Merzouki, R., Bouamama, B. O., and Dauphin-Tanguy, G., 2007. "Robust fault diagnosis by using bond graph approach". IEEE/ASME Transaction On Mechatronics, 12.

[11] Boulon, L., Hissel, D., Bouscayrol, A., and Péra, M. C., 2008. "Multi physics modelling and representation of power and energy sources for hybrid electric vehicles". IEEE Vehicle Power and Propulsion Conference (VPPC).

[12] Chartrand, G., 1985. Introductory Graph Theory. New York: Dover.

[13] Tsuge, Y., Shiozaki, J., Matsuyama, H., and OŠShima, E., 1995. "Fault diagnosis algorithms based on signed directed graphs and its modifications". Indian Chemical Engineering Symposium Series, 92.

[14] Mosterman, P., and Biswas, G., 1999. "Diagnosis of continuous valued systems in transient operating regions". IEEE Trans.Syst. Man Cy. A, 29, p. 554 Ü565.

[15] Geitner, G., 2006. "Power flow diagrams using a bond graph library under simulink". In proc.of IEEE-IECON'06.

[16] Samantaray, K., Medjaher, K., Boumama, B. O., Staroswiecki, and Dauphin-Tanguy, G., 2005. "Diagnostic bond graph for online fault detection and isolation". Simulation modeling practice and theory.

[17] Ould-Bouamama, B., and Dauphin-Tanguy, G., 2006. "Modelisation par bond graph. application aux systemes energetiques". Techniques de l'ingenieur, BE 8 281, p. 16p.

[18] Karnopp, D., and Rosenberg, R., 1991. Systems Dynamics: A Unified Approach. John Wiley \& Sons.

[19] Chatti, N., Bouamama, B. O., Gehin, A., and Merzouki, R., 2014. "Signed bond graph for multiple faults diagnosis". $\check{T}$ International Scientific Journal Engineering Applications of Artificial Intelligence, 36, pp. 134-147.

[20] B. Ould-Bouamama, N. Chatti, A. G., 2014. "Sbg for health monitoring of fuel celle system". ICREGAŠ14-Renewable Energy: Generation and application.

[21] Hautier, J. P., and Faucher, J., 1996. "Le graphe informationnel causal". Bulletin de lŠUnion des Physiciens, 90, pp. 167-189.

[22] Lhomme, W., 2007. "Gestion d'énergie de véhicule hybrides basée sur la représentation énergétique macroscopique”. $\mathrm{PhD}$ thesis.

[23] Hissel, D., Turpin, C., Boulon, L., Bouscayrol, A., Péra, M.-C., and Rael, S., 2008. “A review on existing modeling methodologies for pem fuel cell systems". In proc. of FDFC'08.

[24] Bouscayrol, A., Guillaud, X., Hautier, J. P., and Delarue, P., 2000. "Macromodelisation pour les conversions electromecaniques : application a la commande des machines electriques". Revue Internationale de Genie Electrique, $\mathbf{3}$, pp. 257-282.

[25] Bouscayrol, A., Delarue, P., and Guillaud, X., 2005. "Power strategies for maximum control structure of a wind energy conversion system with synchronous machine". Renewable Energy, 30, pp. 2273-2288.

[26] Boulon, L., Hissel, D., Bouscayrol, A., Péra, M.-C., and Delarue, P., 2008. "Maximal and practical control structure of a pem fuel cell system based on energetic macroscopic representation". proc. Of FDFC'08, p. 11p.

[27] Hernandez, A., Hissel, D., and Outbib, R., 2010. "Modeling and fault diagnosis of a polymer electrolyte fuel cell using electrical equivalent analysis". IEEE Transactions on Energy Conversion, 25.

[28] Noiying, P., 2013. “Modélisation locale d'une cellule de pile à combustible pour l'étude de systèmes électriques". PhD thesis.

[29] Larminie, J., and Dicks, A., 2003. Fuel Cell systems explained, second edition. John Wiley \& Sons.

[30] Hissel, D., Péra, M. C., Bouscayrol, A., and Chrenko, D., 2008. "Représentation énergétique macroscopique d'une pile à combustible". Revue Internationale de Genie Electrique, 11, pp. 4-5.

[31] Peraza, C., Diaz, J. G., Arteaga-Bravo, F. J., Villanueva, C., and Gonzales-Longatt, F., 2008. "Modeling and simulation of pem fuel cell with bond graph and 20sim". American Control Conference.

[32] Rabih, S., Turpin, C., and Astier, S., 2008. "Bond graph model of a pem fuel cell stack". International Conference on Renewable Energies and Power Quality.

[33] Saisset, R., Fontes, G., Turpin, C., and Astier, S., 2006. "Bond graph model of a pem fuel cell". Journal of Power Sources, 156, pp. 100-107. 
[34] Hung, Y. H., Lin, P. H., Wu, C. H., and Hong, C. W., 2008. "Real-time dynamic modeling of hydrogen pemfcs". Journal of the Franklin Institute, pp. 182-203.

[35] McCain, B. A., and Stefanopoulou, A. G., 2006. "Order reduction for a control-oriented model of the water dynamics in fuel cells". International Conference on Fuel Cell Science, Engineering and Technology,.

[36] Chatti, N., Ould-Bouamama, B., Gehin, A.-L., and Merzouki, R., 2013. "Merging bond graph and signed directed graph to improve fdi procedure". European Control Conference.

[37] Schott, P., and Baurens, P., 2006. “cell operation characterization using simulation”. Journal of Power Sources, 156, pp. 85-91.

[38] Schott, P., Poirot, J.-P., and Baurens, P., 2001. "Modélisation et simulation de la source dŠenergie à pile à combustible du véhicule hydro-gen”. Ann. Chim. Sci. Mat, 26, pp. 27-42.

[39] Gerard, M., Poirot-Crouvezier, J.-P., Hissel, D., and Pera, M.-C., 2010. "Oxygen starvation analysis during air feeding faults in pemfc". Journal of Hydrogen Energy, 35, pp. 12295-12307.

[40] Benchouia, N. E., Elias, H. A., Khochemane, L., and Mahmah, B., 2014. "Bond graph modeling approach development for fuel cell pemfc systems". International Journal of Hydrogen Energy, 39, pp. 15224-15231.

[41] Bressel, M., Hilairet, M., Hissel, D., and Ould-Bouamama, B., 2015. "Dynamical modeling of proton exchange membrane fuel cell and parameters identification". 6th International Conference on "Fundamentals \& Development of Fuel Cells", FDFC 2015, Toulouse, France.

[42] Mzoughi, D.and Allagui, H., Khili, N., and Mami, A., 2015. "Bond graph modeling and control of a single pem cell". 6th International Renewable Energy Congress (IREC), Sousse (Tunisia).

[43] Francois, B., Hissel, D., and Iqbal, M., 2005. "Dynamical modelling of a fuel cell and wind turbine dc-linked power system". Electrimacs Conference.

[44] Chrenko, D., Péra, M. C., and Hissel, D., 2007. "uel cell system modeling and control with energetic macroscopic representation". IEEE International Sympsium on Industrial Electronics.

[45] Boulon, L., Pera, M.-C., Delarue, P., Bouscayrol, A., and Hissel, D., 2009. "Causal fuel cell system model suitable for transportation simulation applications". ASME Journal of Fuel Cell Science and Technology, 7.

[46] Solano-Martinez, J., Hissel, D., Pera, M. C., and Amiet, M., 2011. "Practical control structure and energy management of a testbed hybrid electric vehicle". IEEE Transaction on Vehicular Technology, 60.

[47] Baert, J., Pouget, J., Hissel, D., and Péra, M. C., 2011. "Energetic macroscopic representation of a hybrid railway powertrain". IEEE Vehicule Power and Propulsion Conference.

[48] Ettihir, K., Boulon, L., Agbossou, K., Kelouwani, S., and Hammoudi, M., 2012. "Design of an energy management strategy for pem fuel cell vehicules". IEEE International Symposium on Industrial Electronics.

[49] Gauchia, L., Bouscayrol, A., Sanz, J., Trigui, R., and Barrade, P., 2011. "Fuel cell, battery and super capacitor hybrid system for electric vehicule: modeling and control via energetic macroscopic representation". IEEE vehicule power and propulsion conference VPPC.

[50] Boscaino, V., Miceli, R., and Capponi, G., 2013. “A circuit model of a 5kw fuel cell”. International Conference on Clean Electrical Power.

[51] Wingelaar, P. J. H., Duarte, J. L., and Hendrix, M. A. M., 2005. "Dynamic characteristics of pem fuel cells". IEEE Power Electronics Specialists Conference.

[52] Famouri, P., and Gemmen, R. S., 2003. "Eletrochemical circuit model of a pem fuel cell". IEEE Power Engineering Society General Meeting.

[53] Fontes, G., Turpin, C., and Astier, S., 2010. "A large-signal and dynamical circuit model of a h2/o2 pem fuel cell: Description, parameter identification and exploitation”. IEEE Transactions on Industrial Electronics, 5.

[54] Wang, C., Nehrir, M. H., and Shaw, S. R., 2005. "Dynamic models and model validation for pem fuel cell using electrical circuits". IEEE Transaction on Energy Conversion, 20.

[55] Becherif, M., Hissel, D., Gaagat, S., and Wack, M., 2011. "Electrical equivalent model of a proton exchange membrane fuel cell with experimental validation". Renewable Energy, 36, pp. 2582-2588.

[56] Noiying, P., Hinaje, M., Rael, S., and Davat, B., 2011. "Electrical modeling of pemfc based on a 1d analogic description of mass transport". IEEE Vehicle Power and Propulsion Conference.

[57] Beer, C. D., Barendse, P., Pillay, P., Bullecks, B., and Rengaswamy, R., 2013. "Electrical circuit analysis of co poisoning in high temperature pem fuel cell for rapid fault diagnostics". IEEE Energy Conversion Congress and Exposition (ECCE). 
Appendix A: Elements of the Bond Graph formalism

\begin{tabular}{|c|c|}
\hline $\begin{array}{l}\mathrm{Sf} \longmapsto \\
\mathrm{Se} \longrightarrow\end{array}$ & Source of flow or effort \\
\hline $\begin{array}{l}\longmapsto R \\
\longrightarrow R\end{array}$ & Resistive element \\
\hline $\begin{array}{l}\mapsto \mathrm{C} \\
\rightarrow \mathrm{C}\end{array}$ & Capacitive element \\
\hline $\begin{array}{l}\longrightarrow I \\
\longmapsto I\end{array}$ & Inertial element \\
\hline$\stackrel{1}{\mapsto} \underset{\mathrm{GY}}{\stackrel{2}{\longrightarrow}}$ & Gyrator \\
\hline$\underset{\mathrm{n}}{1} \underset{\mathrm{TF}}{\stackrel{2}{\longrightarrow}}$ & Transformer \\
\hline$\stackrel{1}{\longrightarrow} \underset{\sqrt{3}}{0} \stackrel{2}{\longmapsto}$ & Junction 0 \\
\hline$\stackrel{1}{\rightarrow} 1 \stackrel{2}{\rightarrow}$ & Junction 1 \\
\hline
\end{tabular}




\section{Appendix B: Elements of the EMR and MCS formalism}

\begin{tabular}{|l|l|}
\hline & $\begin{array}{l}\text { Multi physical domain converter } \\
\text { (without energy accumulation) }\end{array}$ \\
\hline
\end{tabular}

